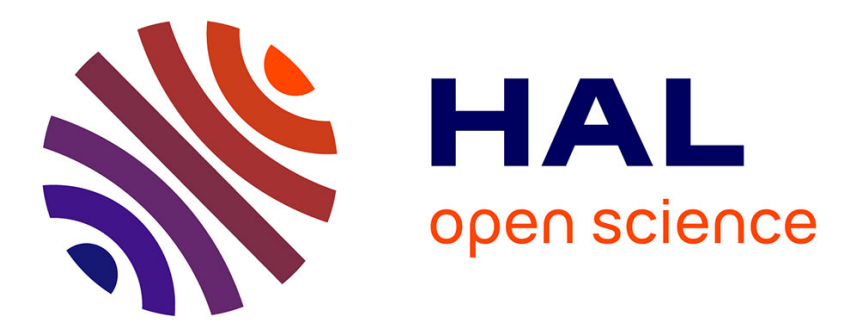

\title{
Charge Transfer Band Gap as an Indicator of Hysteresis in Li-Disordered Rock Salt Cathodes for Li-Ion Batteries
}

Quentin Jacquet, Antonella Iadecola, Matthieu Saubanère, Haifeng Li, Erik. Berg, Jordi Cabana, Marie-Liesse Doublet, Jean-marie Tarascon

\section{- To cite this version:}

Quentin Jacquet, Antonella Iadecola, Matthieu Saubanère, Haifeng Li, Erik. Berg, et al.. Charge Transfer Band Gap as an Indicator of Hysteresis in Li-Disordered Rock Salt Cathodes for LiIon Batteries. Journal of the American Chemical Society, 2019, 141 (29), pp.11452-11464. 10.1021/jacs.8b11413 . hal-02267408

\section{HAL Id: hal-02267408 \\ https://hal.science/hal-02267408}

Submitted on 9 Nov 2020

HAL is a multi-disciplinary open access archive for the deposit and dissemination of scientific research documents, whether they are published or not. The documents may come from teaching and research institutions in France or abroad, or from public or private research centers.
L'archive ouverte pluridisciplinaire HAL, est destinée au dépôt et à la diffusion de documents scientifiques de niveau recherche, publiés ou non, émanant des établissements d'enseignement et de recherche français ou étrangers, des laboratoires publics ou privés. 


\section{Charge Transfer Band Gap as an Indicator of Hysteresis in Li-Disordered Rock Salt Cathodes for Li-Ion Batteries}

Q. Jacquet ${ }^{a, b, c}$, A. Iadecolac ${ }^{c}$, M. Saubanère ${ }^{c, d}$, H. Li ${ }^{e}$, Erik. J. Berg ${ }^{f}$, G. Rousse ${ }^{a, b, c}$, J. Cabana ${ }^{e, g}$, M.-L. Doublet ${ }^{c, d}$, and J.-M. Tarascon ${ }^{a, b, c}$

a Collège de France, Chaire de Chimie du Solide et de l'Energie, UMR 8260, 11 place Marcelin Berthelot, 75231 Paris CEDEX 05, France

${ }^{\mathrm{b}}$ Sorbonne Université, 4 place Jussieu, F-75005 Paris, France

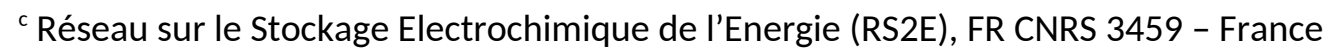

d Institut Charles Gerhardt, CNRS UMR 5253, Université Montpellier, Place E. Bataillon, 34095 Montpellier, France

${ }^{\mathrm{e}}$ Department of Chemistry, University of Illinois at Chicago, Chicago, Illinois 60607, United States

${ }^{\mathrm{f} E l e c t r o c h e m i s t r y ~ L a b o r a t o r y, ~ P a u l ~ S c h e r r e r ~ I n s t i t u t, ~ C H-5232 ~ V i l l i g e n ~ P S I, ~ S w i t z e r l a n d ~}$

${ }^{\mathrm{g}}$ Joint Center for Energy Storage Research (JCESR), Argonne National Laboratory, Lemont, Illinois 60439, United States 


\section{Abstract:}

Disordered rocksalt compounds showing both anionic and cationic redox are being extensively studied for their very high energy storage capacity. While the Mn-based disordered rocksalt compounds show decent energy efficiency, it is drastically lower in the Ni-based materials due to different voltage hysteresis, $0.5 \mathrm{~V}$ and $2 \mathrm{~V}$, respectively. To understand the origin of this difference, we herein report the design of two model compounds $\mathrm{Li}_{1.3} \mathrm{Ni}_{0.27} \mathrm{TaO}_{{ }_{43}} \mathrm{O}_{2}$ and $\mathrm{Li}_{1.3} \mathrm{Mn}_{0.4} \mathrm{Ta}_{0.3} \mathrm{O}_{2}$ and study their charge compensation mechanism through the uptake and removal of Li via an arsenal of analytical techniques. We show that different voltage hysteresis with $\mathrm{Ni}$ or $\mathrm{Mn}$ substitution is due to differences in the way anionic redox proceeds. We rationalized such a finding by DFT calculations and propose this drastic difference to be nested in the smaller charge transfer band gap of the Ni-based compounds compared to the Mn ones. Altogether these findings provide vital guidelines for designing high capacity disordered rocksalt cathode materials based on anionic redox activity for next generation of Li-ion batteries.

\section{Graphical Abstract}

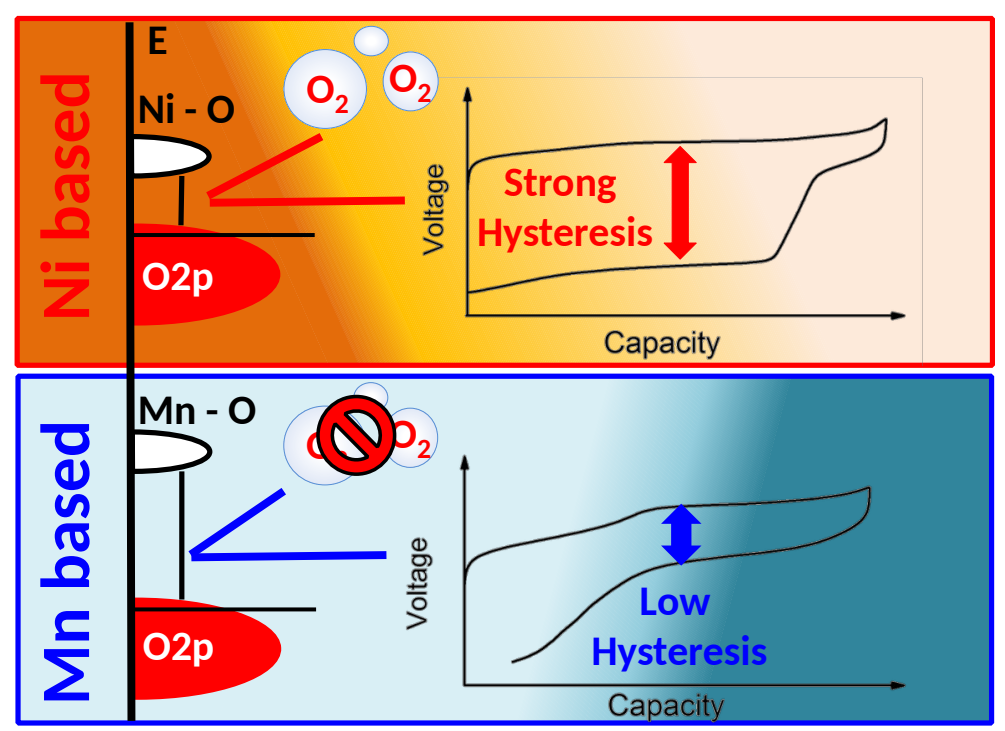




\section{Introduction:}

Electrical energy and transportation are two pillars of our society, and both are provided by fossil fuels, which are unsustainable and polluting resources. To alleviate this issue, great are efforts are being made to make use of renewable energies, for instance coming from wind or sun. However, to succeed in the energy transition based on these intermittent energy sources, energy storage needs to be further developed. Among the storage devices, Li-ion batteries, because of their high energy density ${ }^{1}$, have conquered most of today's portable electronic and EV markets and they stand as serious contenders for grid applications. Despite their widespread use, the energy density of Li-ion battery still needs to be improved to match with the electric cars customers' requirements in terms of autonomy. This mainly calls for the design of new cathode materials with higher capacity and working potential. Along that line, Li-excess disordered rocksalt oxides (DRS) are interesting materials since they show very high capacity, $300 \mathrm{mAh} / \mathrm{g}$ for $\mathrm{Li}_{1.3} \mathrm{Mn}_{0.4} \mathrm{Ti}_{0.3} \mathrm{O}_{2}$ and $250 \mathrm{mAh} / \mathrm{g}$ for $\mathrm{Li}_{1.2} \mathrm{Ni}_{0.33} \mathrm{Ti}_{0.33} \mathrm{Mo}_{0.13} \mathrm{O}_{2}$ compared to commercialized materials $\mathrm{LiNi}_{0.33} \mathrm{Mn}_{0.33} \mathrm{Co}_{0.33} \mathrm{O}_{2} \quad(200$ mAh/g). ${ }^{2-6}$ Both $\mathrm{Li}_{1.3} \mathrm{Mn}_{0.4} \mathrm{Ti}_{0.3} \mathrm{O}_{2}$ and $\mathrm{Li}_{1.2} \mathrm{Ni}_{0.33} \mathrm{Ti}_{0.33} \mathrm{Mo}_{0.13} \mathrm{O}_{2}$ capacities are the result of the combined cationic and anionic redox, being the oxidation/reduction of the transition metal and the oxygen lone pairs, respectively.[Seo] Application-wise, $\mathrm{Li}_{1.2} \mathrm{Ni}_{0.33} \mathrm{Ti}_{0.33} \mathrm{Mo}_{0.13} \mathrm{O}_{2}$ shows less interesting properties compared to $\mathrm{Li}_{1.3} \mathrm{Mn}_{0.4} \mathrm{Ti}_{0.3} \mathrm{O}_{2}$ mostly because of a poor energy efficiency due to a strong voltage hysteresis. Indeed while both compounds have similar redox potentials in oxidation, the Ni-based compounds shows a lower averaged reduction potential of $3 \mathrm{~V}$, due to a sudden drop of voltage of $1.5 \mathrm{~V}$, compared to $3.2 \mathrm{~V}$ in the $\mathrm{Mn}$ based one. Interestingly, this phenomenon can be observed in many Ni-based rocksalt as presented in Table $1^{3,5,7-10}$, but never in Mn-based compounds. The origin of such feature has been investigated in only two studies: i) Lee et al. attributed this phenomena to the formation of a $\mathrm{Li}$ - poor layer at the surface of the material during charge, impeding $\mathrm{Li}$ diffusion for $\mathrm{Li}_{1.2} \mathrm{Ni}_{0.33} \mathrm{Ti}_{0.33} \mathrm{Mo}_{0.13} \mathrm{O}_{2}{ }^{5}$ and ii) Zhao et al. proposed the reduction of $\mathrm{Mn} / \mathrm{Mo}$ due to oxygen release in $\mathrm{Li}_{1.2} \mathrm{Ni}_{0.4} \mathrm{Mn}_{0.2} \mathrm{Mo}_{0.2} \mathrm{O}_{2}{ }^{10}$. To check the validity of these hypotheses, we propose a detailed comparison of two new $\mathrm{Ni}$ and $\mathrm{Mn}$ - based DRS model systems. To synthetize such phases, $d^{0}$ elements are used to stabilize the cation disordering, based on early work by Urban et al. ${ }^{11}$. Numerous $\mathrm{d}^{0}$ elements such as $\mathrm{Ti}^{4+}, \mathrm{Nb}^{5+}$ or $\mathrm{Mo}^{6+}$ have already been used to make Li-based DRS. Herein, we propose to use $\mathrm{Ta}^{5+}$ as $\mathrm{d}^{0}$ element and therefore compare the two phases $\mathrm{Li}_{1.3} \mathrm{Ni}_{0.27} \mathrm{Ta}_{0.43} \mathrm{O}_{2}$ (LNTO) and $\mathrm{Li}_{1.3} \mathrm{Mn}_{0.4} \mathrm{Ta}_{0.3} \mathrm{O}_{2}$ (LMTO) with the aim to 
i) assess the origin of the different discharge potentials between $\mathrm{Mn}$-based and Ni-based compounds, and ii) probe the role of $\mathrm{Ta}^{5+}\left(5 \mathrm{~d}^{0}\right)$ substitution in the overall redox processes, compared to $\mathrm{Nb}^{5+}$ and $\mathrm{Mo}^{6+}\left(4 \mathrm{~d}^{0}\right)$, or $\mathrm{Ti}^{4+}\left(3 \mathrm{~d}^{0}\right)$. The $\mathrm{Li}_{1.3} \mathrm{Ni}_{0.27} \mathrm{Ta}_{0.43} \mathrm{O}_{2}$ and $\mathrm{Li}_{1.3} \mathrm{Mn}_{0.4} \mathrm{Ta}_{0.3} \mathrm{O}_{2}$ compounds were synthesized as single phases and their electrochemical behavior was investigated via complementary techniques such as Online Electrochemical Mass Spectrometry (OEMS), X-ray Absorption Spectroscopy (XAS) and X-Ray Diffraction (XRD). The $\mathrm{Ni}$-based one shows instability against $\mathrm{O}_{2}$ release upon intensive oxidation as opposed to the Mn-one. Additionally, we show that the drop of potential observed in the Ni-based compound is due to the low reduction potential of anionic redox occurring at $1.5 \mathrm{~V}$ compared to $3 \mathrm{~V}$ for the $\mathrm{Mn}$-based one. Both the enhanced gas release and voltage hysteresis for the $\mathrm{Li}_{1.3} \mathrm{Ni}_{0.27} \mathrm{Ta}_{0.43} \mathrm{O}_{2}$, are attributed to its low band gap due to the presence of $\mathrm{Ni}^{3+}\left(\mathrm{d}^{4}\right)$, as shown by DFT calculation. For the sake of clarity, we first briefly describe the synthesis of these compounds together with their general electrochemistry prior to present the mechanism of the Li-removal/uptake in $\mathrm{Li}_{1.3} \mathrm{Ni}_{0.27} \mathrm{Ta}_{0.43} \mathrm{O}_{2}$ and $\mathrm{Li}_{1.3} \mathrm{Mn}_{0.4} \mathrm{Ta}_{0.3} \mathrm{O}_{2}$ separately. Then, we will engage into a theoretical approach focusing on the charge transfer band gap in these materials.

\begin{tabular}{|c|c|c|c|}
\hline Composition & $\begin{array}{l}\text { Potential drop in } \\
\text { discharge }\end{array}$ & Proposed origin & Ref. \\
\hline $\mathrm{Li}_{1.33} \mathrm{Ni}_{0.33} \mathrm{~W}_{0.33} \mathrm{O}_{2}$ & $2 \mathrm{~V}$ & Not explored & 7 \\
\hline $\mathrm{Li}_{1.3} \mathrm{Ni}_{0.27} \mathrm{Nb}_{0.43} \mathrm{O}_{2}$ & $2 \mathrm{~V}$ & Not explored & Yabuuchi et al. ${ }^{3}$ \\
\hline $\mathrm{Li}_{1.2} \mathrm{Ni}_{0.33} \mathrm{Ti}_{0.33} \mathrm{Mo}_{0.16} \mathrm{O}_{2}$ & $1.5 \mathrm{~V}$ & $\begin{array}{l}\text { Kinetic limitation - } \\
\text { formation of } \\
\text { densified surface }\end{array}$ & Lee et al. ${ }^{5}$ \\
\hline
\end{tabular}
$\mathrm{Li}_{1.33} \mathrm{Ni}_{0.33} \mathrm{Mo}_{0.33} \mathrm{O}_{2}$
$1.9 \mathrm{~V}$
Not explored
Yabuuchi et al. ${ }^{8}$ 


$$
\mathrm{Li}_{1.05} \mathrm{Ni}_{0.5} \mathrm{Ti}_{0.3} \mathrm{Nb}_{0.15} \mathrm{O}_{2} \quad 1.8 \mathrm{~V} \quad \text { Not explored Colin et al. }{ }^{9}
$$

Mn or Mo reduction

$\begin{array}{ccl}\mathrm{Li}_{1.2} \mathrm{Ni}_{0.4} \mathrm{Mn}_{0.2} \mathrm{Mo}_{0.2} \mathrm{O}_{2} & 2 \mathrm{~V} & \begin{array}{l}\text { triggered by oxygen } \\ \text { Zhao et al. }{ }^{10}\end{array} \\ & \text { release }\end{array}$

Table 1: Composition, amplitude of the potential drop observed during discharge and the origin of such feature for reported Ni-based compounds.

\section{Experimental details:}

Synthesis: Classical solid state synthesis from the oxide precursors, $\mathrm{NiO}$ (green, Sigma-Aldrich $99 \%$ ), $\mathrm{Mn}_{2} \mathrm{O}_{3}$ (Sigma-Aldrich, 99.9\%), $\mathrm{Ta}_{2} \mathrm{O}_{5}$ (Alfa Aesar, 99.85\%) and with 10\% excess $\mathrm{Li}_{2} \mathrm{CO}_{3}$ (Sigma Aldrich, 99\%), was employed to prepare the $\mathrm{Li}_{1.3} \mathrm{Ni}_{0.27} \mathrm{Ta}_{0.43} \mathrm{O}_{2}$ and $\mathrm{Li}_{1.3} \mathrm{Mn}_{0.4} \mathrm{Ta}_{0.3} \mathrm{O}_{2}$ phases. The reactants were mixed using mortar and pestle before grinding in a planetary ball mill using a zirconia set for 1 hour at $600 \mathrm{rpm}$ for the $\mathrm{Li}_{1.3} \mathrm{Ni}_{0.27} \mathrm{Ta}_{0.43} \mathrm{O}_{2}$ precursors and 12 hours at 600rpm for $\mathrm{Li}_{1.3} \mathrm{Mn}_{0.4} \mathrm{Ta}_{0.3} \mathrm{O}_{2}$ precursors. The powders were fired for $24 \mathrm{~h}$ at $900^{\circ} \mathrm{C}$ in air for $\mathrm{Li}_{1.3} \mathrm{Ni}_{0.27} \mathrm{Ta}_{0.43} \mathrm{O}_{2}$ and under argon flux for $\mathrm{Li}_{1.3} \mathrm{Mn}_{0.4} \mathrm{Ta}_{0.3} \mathrm{O}_{2}$.

Electrochemical testing: All the electrochemical characterization was performed in Swagelok-type cells. The positive electrode material was grinded in SPEX-type ball mill for 60 min with 20\% carbon SP. Note that shorter ball mill time resulted in poorer electrochemical properties as presented Figure S1. Then, the active material and carbon mix was embedded into a PTFE matrix. The final electrode showed the following composition: $72 \%$ active material/18\% carbon/10\% PTFE. Li metal was used as anode. Whatmann GF/D borosilicate glass fibers sheets were used as separators and the electrolyte was LP100 (1/1/3 EC/PC/DMC with 1 M LiPF 6 ). Cells were assembled in Ar-filled glovebox. Galvanostatic cycling was performed at $\mathrm{C} / 20$ (meaning $1 \mathrm{Li}$ is extracted in 20 h). Ex situ samples were washed with DMC inside an Ar-filled glovebox before being dried under vacuum. Galvanostatic Intermittent Titration Technique (GITT) was performed using OCV period of $5 \mathrm{~h}$.

Structural characterization: XRD measurements are performed using a BRUKER D8 Advance diffractometer with $\mathrm{Cu}$ Ka radiation $\left(\lambda_{\mathrm{Ka} 1}=1.54056 \AA, \lambda_{\mathrm{Ka} 2}=1.54439 \AA\right)$ and a Lynxeye XE detector. Operando experiment are performed using the same diffractometer with a home-made airtight electrochemical cell equipped with a Be window ${ }^{12}$. Neutron powder diffraction (NPD) patterns were measured on the D1B powder diffractometer at ILL (Institut Laue-Langevin) with $\lambda=1.2911$ Å. Rietveld refinements were performed using the FullProf program ${ }^{13}$. 
Hard X-ray Absorption Spectroscopy (XAS): Operando XAS measurements at the Ni and Mn K-edges and ex situ measurements at the $\mathrm{Ta}_{\mathrm{L}_{3}}$-edge were performed in transmission mode at the ROCK beamline ${ }^{14}$ of synchrotron SOLEIL (France). A Si (111) channel-cut quick-XAS monochromator with an energy resolution of $0.8 \mathrm{eV}$ at $8 \mathrm{keV}$ was used. The intensity of the monochromatic X-ray beam was measured by three consecutive ionization detectors. For the operando measurement, the in situ electrochemical cell was placed between the first and the second ionization chambers. All samples were prepared as self-standing PTFE films of the active material and cycled at $\mathrm{C} / 20$. Successive spectra were collected at a rate of $2 \mathrm{~Hz}$ and averaged out over periods of 5 minutes. The energy calibration was established with simultaneous absorption measurements on $\mathrm{Ni}, \mathrm{Mn}$ or $\mathrm{Zn}$ foils placed between the second and the third ionisation chamber. All data was treated using the Demeter package for energy calibration and normalization. ${ }^{15}$ For the operando data, the normalized spectra were globally analyzed with Principal Component Analysis (PCA $)^{16}$ in order to individuate the orthogonal components able to describe the whole evolution during cycling. The number of principal components was then used as basis for Multivariate Curve Resolution-Alternating Least Squares (MCR-ALS) analysis. ${ }^{17}$ Finally, the reconstructed components as well as the ex situ spectra were fitted using the Artemis software. Fourier transforms of $k^{2}$ weighted EXAFS oscillations were carried out in k-range from $3.5 \AA^{-1}$ to $12 \AA^{-1}$ for Ni K-edge and $5.1 \AA^{-1}$ to $11 \AA^{-1}$ for the Mn K-edge. For Ta $\mathrm{L}_{3}$-edge, the Fourier transforms of $\mathrm{k}^{3}$ weighted EXAFS oscillations were carried out in k-range from $3.7 \AA^{-1}$ to $13.7 \AA^{-1}$ and the fitting was performed in R-range from 1.0 to $3.5 \AA$. EXAFS amplitudes and phase-shifts were calculated by FEFF7. $\mathrm{Mn}_{2} \mathrm{O}_{4}$ reference for XAS was prepared by full delithiation of the $\mathrm{LiMn}_{2} \mathrm{O}_{4}$ spinel.

Soft XAS: measurements at the Ni L-edge, Mn L-edge and O K-edge were performed at beamline 4-ID-C of the Advance Photon Source at Argonne National Laboratory. Transport and sample loading was performed minimizing exposure to air. Data were measured simultaneously under both the total electron yield (TEY) mode with the sample photocurrent at $\sim 10^{-9}$ Torr and total fluorescence yield (TFY) mode by a silicon drift diode detector. The angle of X-ray incidence in TFY mode was adjusted to minimize the self-absorption effect while still being bulk sensitive. Data was obtained at a spectral resolution of $\sim 0.2 \mathrm{eV}$, with a $2 \mathrm{~s}$ dwell time. During the measurement, three scans were performed at each absorption edge for each sample, and scans were then averaged to maximize the signal-to-noise ratio. Oxygen K-edge XAS was calibrated measuring simultaneously $\mathrm{Sr}_{2} \mathrm{RuO}_{4}$ as a reference.

Online Electrochemical Mass Spectrometry (OEMS): A detailed schematic of the OEMS setup is provided elsewhere. ${ }^{18}$ Briefly, the OEMS operates with a quadrupole mass spectrometer (QMS 200, Pfeiffer, Germany) for partial pressure measurements and a pressure transducer (PAA-33X, Keller Druck AG, Switzerland) for total cell pressure recordings, temperature, and internal volume determination. Swagelok stainless steel gas pipes and fittings ( $3 \mathrm{~mm}$ compression tube fittings, Swagelok, OH, USA) are employed to connect a homemade OEMS cell, a set of solenoid valves (2-way magnetic valve, Series 99, silver-plated nickel seal, Parker, USA) and a scroll pump (nXDS15i, EDWARDS GmbH, UK) for efficient flushing. The valves are electronically controlled with a Solid 
State Relay Module (NI 9485 measurement System, National Instruments, TX, USA) connected to a computer with a LabView Software (NI Labview 2013, National Instruments, TX, USA). For partial pressure and gas evolution rate analysis $0.8 \mathrm{~mL}$ of gas are extracted from the headspace $(\sim 4 \mathrm{~mL})$ of the cell and replaced by pure $\operatorname{Ar}$ (quality 5.0). Calibration gas bottles were utilized to relate the MS ion-current signals at $\mathrm{m} / \mathrm{z}=32$ and 44 to known concentrations of $\mathrm{O}_{2}$ and $\mathrm{CO}_{2}\left(1000 \mathrm{ppm}\right.$ of $\mathrm{O}_{2}$ and $\mathrm{CO}_{2}$ in $\mathrm{Ar}$, respectively), before and after the measurement.

DFT: Spin-polarized density functional theory (DFT) calculations were performed using the plane-wave density functional theory VASP (Vienna ab initio simulation package) code ${ }^{19,20}$ within the generalized gradient approximation of Perdew-Burke-Ernzerhof (PBE) to describe electron exchange and correlation ${ }^{21}$. The rotationally invariant Dudarev method $(\mathrm{DFT}+\mathrm{U})^{22}$ was used to correct the self-interaction error of conventional DFT for correlated d-electrons with $\mathrm{U}=6.4 \mathrm{eV}$ and $5 \mathrm{eV}$ for the $\mathrm{Ni}$ - and $\mathrm{Mn}$-based compounds, respectively. Homemade cluster expansion code has been used to identify low energy cationic configurations in the pristine materials, $\mathrm{Li}_{1.3} \mathrm{Ni}_{0.27} \mathrm{Ta}_{0.43} \mathrm{O}_{2}$ and $\mathrm{Li}_{1.3} \mathrm{Mn}_{0.4} \mathrm{Ta}_{0.3} \mathrm{O}_{2}$. Note that for the latter, the chemical composition of the theoretical model is $\mathrm{Li}_{1.3} \mathrm{Ni}_{0.3} \mathrm{Ta}_{0.4} \mathrm{O}_{2}$. A unit cell of 40 atoms was used with cell parameters of $a=6 \AA, b=6 \AA, c=$ $12 \AA, \alpha=90^{\circ}, \beta=90^{\circ}, \gamma=60^{\circ}$. The structural search was carried out in two steps. First, Ta networks minimizing the unfavorable Ta - Ta next-nearest neighbors (NNN) were chosen. Indeed, the energy of the structure is drastically influenced by the number of NNN Ta - Ta interactions as shown in Figure S22. Second, all the possible $\mathrm{Li}$ and $\mathrm{Ni} / \mathrm{Mn}$ configurations were generated and the most stable structures were selected for further analysis. To assess the validity of our approach, we computed the DFT energy of the 50 lowest energy structures deduced from our cluster expansion calculations, and compare these energies to the DFT energy of random cation orderings, as shown in Figure S23. It can be seen that using our cluster expansion code, we could identify low energy cation ordering with negligible computational cost. Convex Hull diagrams were then produced from the delithiation of the chosen structural models. The voltage profiles, Bader charges, atomic distances and $\mathrm{O}_{2}$ release enthalpies were computed and showed good agreement with experiments as shown in Figure S24, S25 and S26.

\section{Results.}

$\mathrm{Li}_{1.3} \mathrm{Ni}_{0.27} \mathrm{Ta}_{0.43} \mathrm{O}_{2}$ (LNTO) and $\mathrm{Li}_{1.3} \mathrm{Mn}_{0.4} \mathrm{Ta}_{0.3} \mathrm{O}_{2}$ (LMTO) were synthetized via solid state method. The precursors were ground for $1 \mathrm{~h}$ for LNTO and $12 \mathrm{~h}$ for LMTO and fired at high temperature under air for the LNTO and argon for the LMTO. The composition were chosen so that the Li content is similar in both compounds, with $\mathrm{Ni}, \mathrm{Mn}$ and $\mathrm{Ta}$ being at the $2+, 3+$ 
and $5+$ oxidation states, respectively. The structure of these new compounds was determined by XRD coupled to NPD which patterns are presented Figure S2 and Figure 1 ab). XRD and NPD are complementary here as they provide different contrast between atoms $\left(Z_{L i}=3\right.$ and $b_{L i}=-1.90 \mathrm{fm}, Z_{M n}=25$ and $b_{M n}=-3.73 \mathrm{fm}, Z_{N i}=28$ and $b_{N i}=10.3 \mathrm{fm}$, and $Z_{T a}=73$ and $\left.b_{T a}=6.91 \mathrm{fm}\right)$. Both products crystalize in $F m-3 m$ space group with cell parameters $a=$ 4.1990(10) $\AA$ and $a=4.1975(11) \AA$ for LNTO and LMTO, respectively (Table S1). Their structure is a rocksalt structure with all the cations randomly distributed over the $4 a$ Wyckoff position as it can be seen on the schematic Figure 1. The electrochemical behavior of LNTO and LMTO as cathode for Li-ion battery was investigated. The $1^{\text {st }}, 2^{\text {nd }}$ and $10^{\text {th }}$ cycles for each compound are presented in Figure $1 \mathrm{c}-\mathrm{d}$ ). LNTO and LMTO show discharge capacities of $220 \mathrm{mAh} / \mathrm{g}$ and $180 \mathrm{mAh} / \mathrm{g}$, respectively. They correspond to the extraction/insertion of $1.1 \mathrm{Li}$ for LNTO and $0.9 \mathrm{Li}$ for LMTO. Although the capacity of LNTO is higher than LMTO, the Ni-based compound shows a lower average discharge potential since only $0.25 \mathrm{Li}$ are inserted above $3 \mathrm{~V}$ compared to $0.6 \mathrm{Li}$ for LMTO. This low average voltage has been observed in other $\mathrm{Ni}$-based disordered rocksalt compounds and it is detrimental for the energy density and energy efficiency, hence the need to understand its origin. Is it related to diffusion issues, cationic vs. anionic redox competition, or Li-driven structural changes? To answer these questions, complementary operando XAS, OEMS and XRD measurements were performed. 


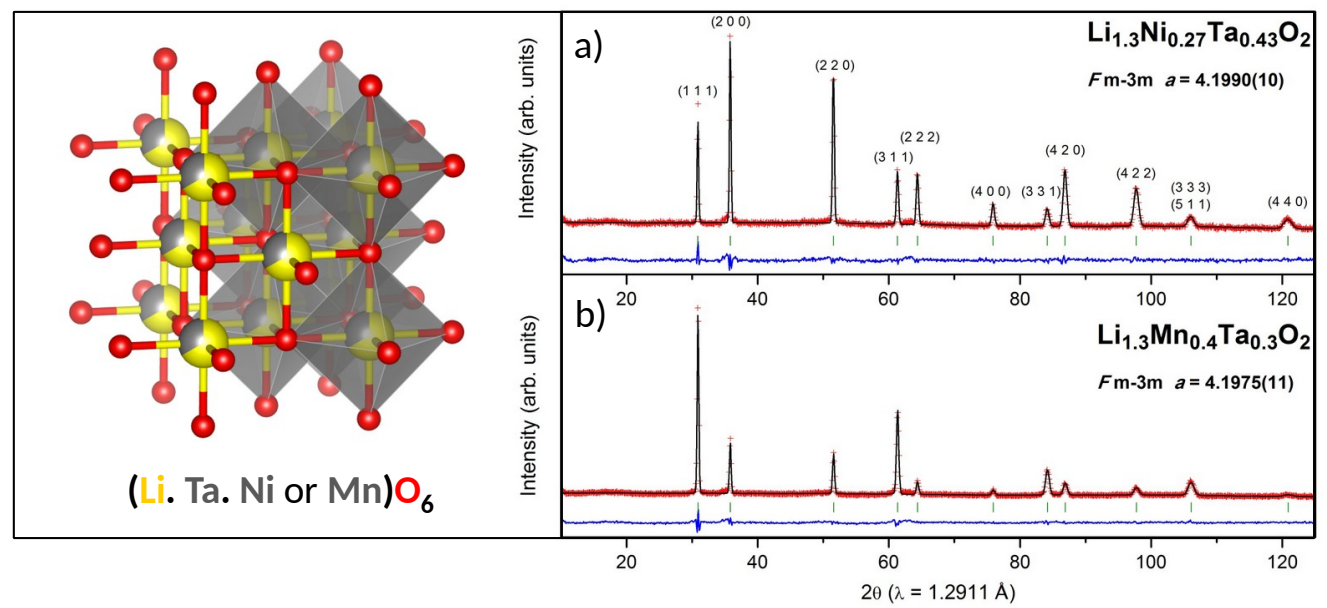

c)

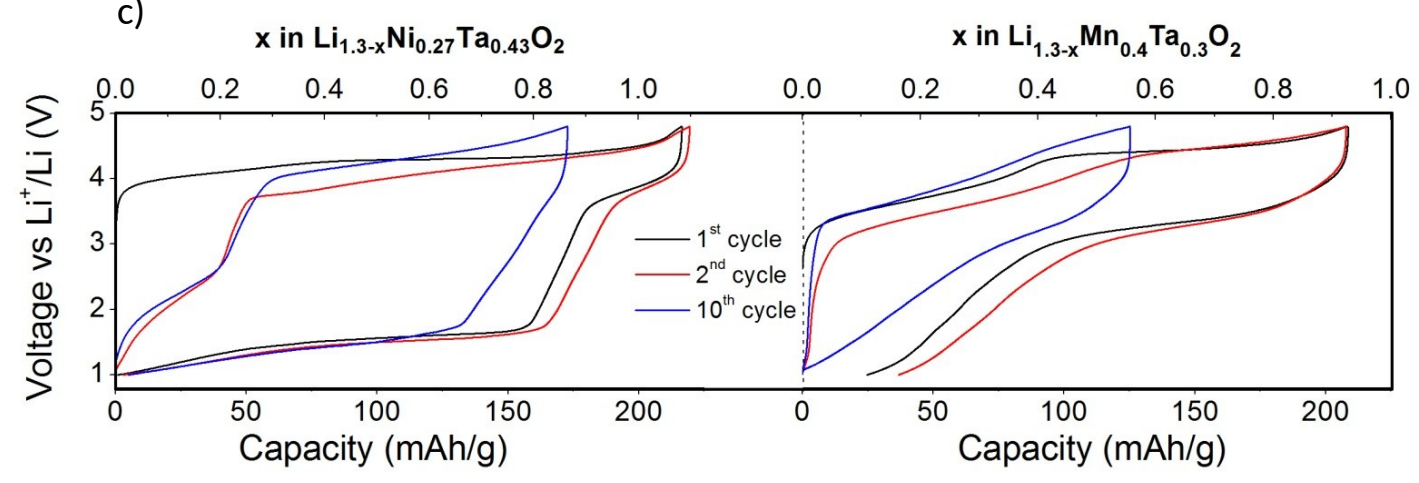

Figure 1: a) and b) Rietveld refinement of NPD patterns of $\mathrm{Li}_{1.3} \mathrm{Ni}_{0.27} \mathrm{Ta}_{0.43} \mathrm{O}_{2}$ and $\mathrm{Li}_{1.3} \mathrm{Mn}_{0.4} \mathrm{Ta}_{0.3} \mathrm{O}_{2}$, respectively. The red crosses, black continuous line and bottom blue line represent the observed, calculated, and difference patterns respectively. Vertical green tick bars are the Bragg positions. c) Voltage-composition curve of $1^{\text {st }}, 2^{\text {nd }}$ and $10^{\text {th }}$ cycles of the galvanostatic cycling of LNTO and LMTO in the left and right panels, respectively.

\section{Mechanism of $\mathrm{Li}$ removal/uptake in $\mathrm{Li}_{1.3} \mathrm{Ni}_{0.27} \mathrm{Ta}_{0.43} \mathrm{O}_{2}$}

The voltage-composition curve for LNTO shows 6 distinct processes: 3 in charge and 3 in discharge, hereafter called CN1, CN2, CN3, DN4, DN5 and DN6, as highlighted in Figure 2-a) (C, D and N stand for "Charge", "Discharge" and "Nickel", respectively). Upon charge, the three processes $\mathrm{CN} 1, \mathrm{CN} 2$, and $\mathrm{CN} 3$ happen at $4 \mathrm{~V}, 4.3 \mathrm{~V}$ and $4.5 \mathrm{~V}$ as deduced from the dQ/ $\mathrm{dV}$ curve and account for the extraction of $0.3,0.4$ and $0.4 \mathrm{Li}$, respectively. Upon discharge, 
the processes DN4, DN5, and DN6 occur at $3.8 \mathrm{~V}, 1.7 \mathrm{~V}$ and $1.3 \mathrm{~V}$ and correspond to the insertion of $0.25,0.5$ and $0.3 \mathrm{Li}$, respectively. Concerning the $2^{\text {nd }}$ charge, a new redox process can be seen centered around $1.7 \mathrm{~V}$. Its capacity scales with the capacity of DN6, hence showing their correlation (Figure S3), however its origin is not yet understood.

Next, to determine the corresponding oxidation-reduction process, several cells were made and oxidized to reach different SOC prior to be discharged to $1.5 \mathrm{~V}$ Figure $2 \mathrm{~b}-\mathrm{c}$ ). Interestingly, when charging over CN1, the reduction curve is mainly composed of DN4 implying the link between both. Moreover, there is appearance of DN5 when further charging, hence a clear connection between CN2-CN3 and DN5 with however a large voltage difference. Worth mentioning is that the capacity of DN4 decreases with increasing SOC and this trend is even more severe at $55^{\circ} \mathrm{C}$. Moreover, despite strong polarization observed during DN5 on the GITT curve (Figure 2-d) equilibrium potential do not reach $3.5 \mathrm{~V}$ implying that the observed voltage difference is not only kinetic but also enlists a thermodynamic limitation suggesting different reduction and oxidation paths. Thus, could such an effect be related to a peculiar charge compensation mechanism having sluggish kinetics associated with the anionic redox species as previously reported in Li-rich materials? ${ }^{23}$
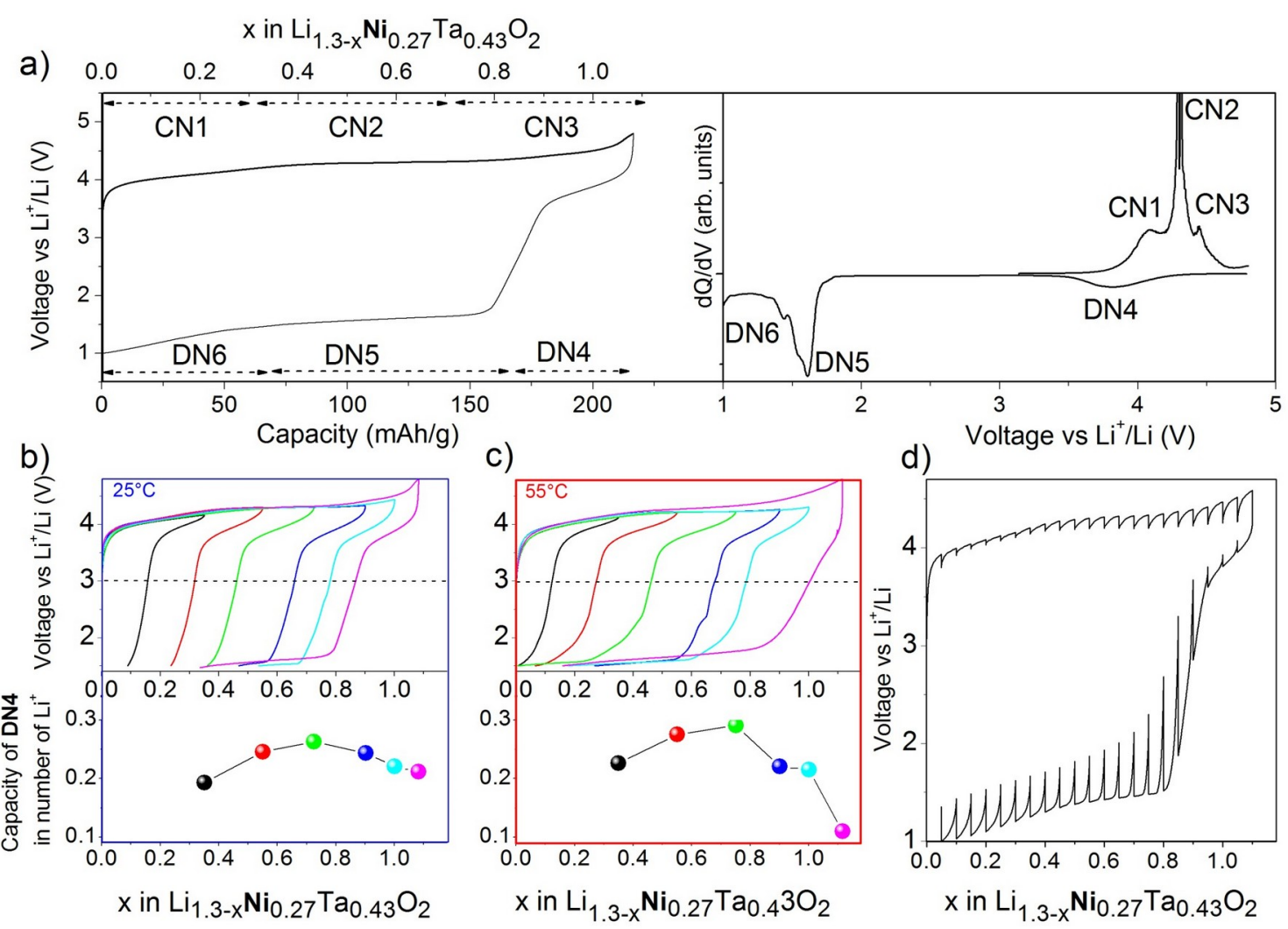
Figure 2: a) Voltage-composition curve of the $1^{\text {st }}$ galvanostatic cycle and its $d Q / d V$ profile, on the left and right panels respectively. b) and c) voltage-composition curve of the $1^{\text {st }}$ cycle with different states of charge (top) together with the capacity of DN4 (>3 V) depending on the SOC (bottom) at $25^{\circ} \mathrm{C}$ and $55^{\circ} \mathrm{C}$. d) GITT measurement performed on the $1^{\text {st }}$ cycle of LNTO.

To clarify this point we used operando $\mathrm{Ni} \mathrm{K}$-edge and ex situ $\mathrm{Ni}_{\mathrm{L}_{3}}$-edge, $\mathrm{Ta}_{\mathrm{L}_{3}}$-edge and $\mathrm{O} \mathrm{K}$ edge XAS to determine the evolution of $\mathrm{Ni}, \mathrm{Ta}$, and $\mathrm{O}$ oxidation states during cycling. First, we monitor the variation of $\mathrm{Ni}$ oxidation state by exploiting, operando the $\mathrm{Ni} \mathrm{K}$-edge position during the electrochemical cycling that we compare with standards, namely $\mathrm{NiO}\left(\mathrm{Ni}^{2+}\right)$ and $\mathrm{LiNiO}_{2}\left(\mathrm{Ni}^{3+}\right)$ as presented in Figure 3-a and Figure S4. The Ni oxidation state is close $2+$ in the pristine compound and increases up to nearly $3+$ during the first part of charge (CN1 and CN2). Upon further charging, there is a reduction of $\mathrm{Ni}^{3+}$ which becomes nearly $\mathrm{Ni}^{2.5+}$ at the end of charge (Figure S5). During DN4, the oxidation state of Ni converts back to $\approx 2$ and stays constant during DN5 and DN6.

The XAS spectra evolution during the electrochemical cycle was further exploited using Principal Component Analysis (PCA) combined to Multivariate Curve Resolution-Alternating Least Squares (MCR-ALS). Three components were identified and both their concentration evolution and their corresponding EXAFS were analyzed and presented in Figure 3 b-c, Figure S6 and Table S2. The $1^{\text {st }}$ and $2^{\text {nd }}$ components correspond to the pristine material and the phase having solely $\mathrm{Ni}^{3+}$, respectively. The $3^{\text {rd }}$ component appears in the middle of the charge, end of CN2. Its concentration increases gradually up to $60 \%$ at the end of DN4 and stays constant during the rest of the discharge. In this component, $\mathrm{Ni}$ is in the same oxidation state than in the pristine, $\approx 2+$, as determined from their edge position (Figure S7) and their EXAFS signal showing similar $\mathrm{Ni}-\mathrm{O}$ environments as opposed to a distorted environment (Jahn -Teller distortion) for the $2^{\text {nd }}$ component. The main difference between the pristine and the $3^{\text {rd }}$ component is nested in the $\mathrm{Ni}-\mathrm{M}$ environment. Indeed, the values obtained for the $\mathrm{Ni}$ - Ni distances, the $\mathrm{Ni}$ - Ta distances and the related Debye-Waller factors are higher in the $3^{\text {rd }}$ component indicating a higher atomic disorder of the end of discharge compound compared to the pristine (Table S2). Note that Ni K-edge and $\mathrm{Ni}_{\mathrm{L}_{3}}$-edge data measured on ex situ samples are consistent with the operando data as presented in Figure S8 and Figure S9. 
a)

$\mathrm{x}$ in $\mathrm{Li}_{1.3-\mathrm{x}} \mathrm{Ni}_{0.27} \mathrm{Ta}_{0.43} \mathrm{O}_{2}$

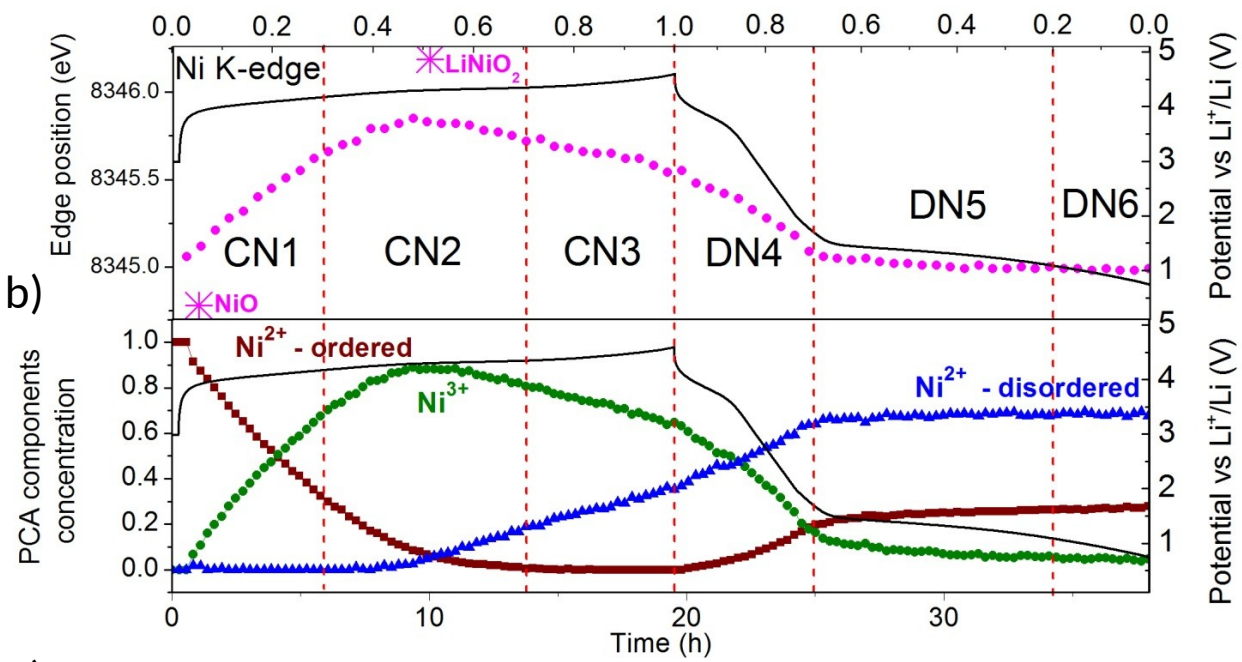

c)

\begin{tabular}{|c|ccccc|cc|cc|}
\hline \multirow{2}{*}{$\begin{array}{c}\text { EXAFS fitting of PCA } \\
\text { components }\end{array}$} & \multicolumn{4}{c}{$1^{\text {st }}$ shell Ni - O } & \multicolumn{3}{c|}{$2^{\text {nd }}$ shell Ni - Ni } & $2^{\text {nd }}$ shell Ni - Ta \\
\cline { 2 - 9 } & $\mathrm{CN}$ & $\mathrm{d}(\mathrm{Ni}-\mathrm{O})$ & $\mathrm{CN}$ & $\mathrm{d}(\mathrm{Ni}-\mathrm{O})$ & $\mathrm{CN}$ & $\mathrm{d}(\mathrm{Ni}-\mathrm{Ni})$ & $\mathrm{CN}$ & $\mathrm{d}(\mathrm{Ni}-\mathrm{Ta})$ \\
\hline $\mathrm{Ni}^{2+}-$ Ordered & 6 & $2.068(2)$ & & & 1.8 & $2.988(7)$ & 2.4 & $3.04(2)$ \\
$\mathrm{Ni}^{3+}-$ Jahn-Teller & 4 & $1.940(3)$ & 2 & $2.11(2)$ & 1.8 & $2.958(6)$ & 2.4 & $3.22(3)$ \\
$\mathrm{Ni}^{2+}-$ Disordered & 6 & $2.048(2)$ & & 1.8 & $3.02(2)$ & 2.4 & $3.25(4)$ \\
\hline
\end{tabular}

d)
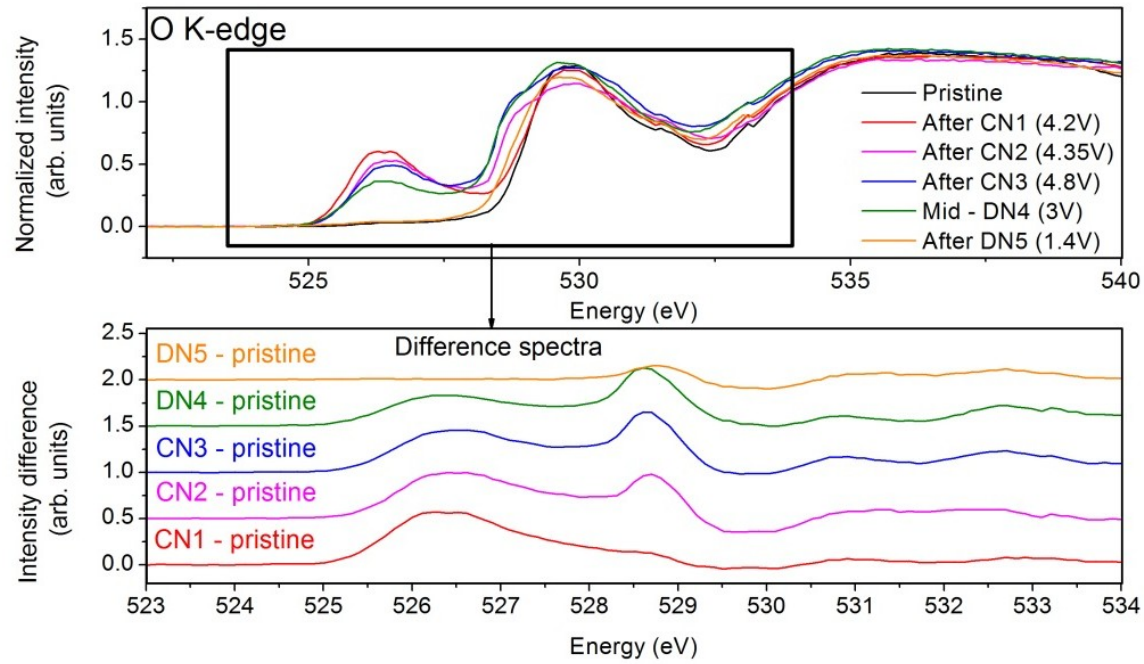

Figure $3:$ a) Evolution of the Ni K-edge position (pink) during operando measurement for the $1^{\text {st }}$ cycle of LNTO together with the voltage-composition curve (black). The value of the edge position is the energy at 0.8 of the edge step. Edge position of $\mathrm{NiO}$ and $\mathrm{LiNiO}_{2}$ are given as reference for $\mathrm{Ni}^{2+}$ and $\mathrm{Ni}^{3+}$, respectively. b) Evolution of the concentration of the components deduced from MCR-ALS during operando measurement, in brown, green, and blue, together with the voltage-composition curve in black. c) Table summarizing the principal information extracted from the EXAFS fitting. d) TFY O K-edge XAS spectra for ex situ samples during the 
charge and discharge, together with the difference spectra between the pristine and the spectra of the ex situ samples in the bottom insert.

Ta $\mathrm{L}_{3}$-edge and $\mathrm{O} \mathrm{K}$-edge measurements were performed on ex situ samples recovered from $\mathrm{Li}_{1.3} \mathrm{Ni}_{0.27} \mathrm{Ta}_{0.43} \mathrm{O}_{2} / \mathrm{Li}$ cells stopped at various states of charge/discharge; after CN1 (4.2 V and $\mathrm{x}$

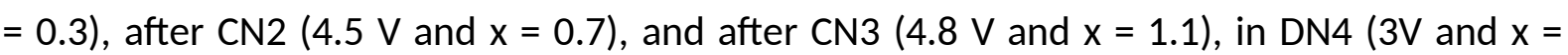
0.85 ) and after DN5 (1.2 $\mathrm{V}$ and $\mathrm{x}=0.3)$. Concerning Ta, for all samples the edge position is similar to the one in $\mathrm{Ta}_{2} \mathrm{O}_{5}$, spotted from the maximum of the first derivative of the normalized intensity (Figure S10), showing Ta stays in the 5+ oxidation state during cycling. However, the white line shape and intensity changes show evolution of the Ta environment during Li removal/uptake. To better assess these changes, analysis of EXAFS oscillations was carried out (Figure S11). It shows that while the average $\mathrm{Ta}-\mathrm{O}$ and $\mathrm{Ta}-\mathrm{M}$ ( $\mathrm{M}$ being $\mathrm{Ni}$ and Ta) distances stay nearly constant during the Li removal/uptake, approximately $1.95 \AA$ and $3.1 \AA$, the distortion coefficient of the $\mathrm{TaO}_{6}$ octahedron, calculated from the mean deviation of Ta-O bond lengths, changes substantially (Table S3). From these results, we concluded that $\mathrm{Ta}$ is not oxidized/reduced during the electrochemical cycling but suffers from modification of its coordination shell, which is highly distorted at the end of charge (CN3) and at the beginning of discharge (DN4).

Altogether, the previous findings dealing with the Ni and Ta redox during the $1^{\text {st }}$ cycle lead us to hypothesize that anionic redox is responsible for the charge compensation mechanism during CN2, CN3 and DN5. To prove this hypothesis, we analyzed the pre-edge features (525 - $532 \mathrm{eV}$ ) of the $\mathrm{O} \mathrm{K}$-edge spectra (Figure 3-d). Two main features at $526.5 \mathrm{eV}$ and $530 \mathrm{eV}$ can be observed. They correspond to electronic transitions from $\mathrm{O}$ 1s into hybridized oxygen $2 p$ states with nd cations. Using O pDOS computed via DFT calculations (Figure S12), we show that the $526.5 \mathrm{eV}$ feature corresponds to Ni-O states which appears solely in presence of $\mathrm{Ni}^{3+}$, while the $530 \mathrm{eV}$ signal is reminiscent of both $\mathrm{Ni}-\mathrm{O}$ and $\mathrm{Ta}-\mathrm{O}$ states. By subtracting the pristine from the ex situ spectra (Fig. 3e bottom) we highlight its evolution during the $1^{\text {st }}$ cycle which is mainly centered at $526.5 \mathrm{eV}$ and $528.7 \mathrm{eV}$. The $526.5 \mathrm{eV}$ feature intensity is maximum after $\mathrm{CN} 1$ and decreases during $\mathrm{CN} 2, \mathrm{CN} 3$ and DN4 directly following the presence of $\mathrm{Ni}^{3+}$ in agreement with DFT calculations. The second feature at higher energy (528.7 eV) 
which appears during CN2 and increases during CN3, clearly suggest the removal of some electronic density on the oxygen atoms. Since neither $\mathrm{Ni}$ nor Ta is active in this region of the charge, the presence of the $528.7 \mathrm{eV}$ is a direct evidence of anionic redox. Interestingly, the $528.7 \mathrm{eV}$ signal remains constant during DN4 and fully disappears in DN5 as expected. This does not come as a full surprise as other studies have been successfully observing anionic redox in the $\mathrm{O}$ K-edge pre edge features. ${ }^{24}$ In short, we have shown that $\mathrm{Ni}$ oxidation/reduction happens at $\approx 3.9 \mathrm{~V}$ with limited polarization $\approx 100 \mathrm{mV}$ while anionic redox occurs at $4.2 \mathrm{~V}$ in charge and $1.5 \mathrm{~V}$ in discharge, clearly implying that anionic redox is therefore responsible for the large voltage hysteresis observed in LNTO.

To better understand the characteristics of anionic redox in LNTO, namely the stability of the oxidized oxygen species towards $\mathrm{O}_{2}$ release, OEMS experiments were performed. The results, presented in Figure 4-a, show initially no gas evolution upon oxidation. In contrast, there is a copious amount of $\mathrm{CO}_{2}$ and $\mathrm{O}_{2}$ produced inside the cell as soon as we reach the CN3 process. Interestingly, this gas production is concomitant with the partial reduction of $\mathrm{Ni}^{3+}$ suggesting that a fraction of the released oxygen atoms in $\mathrm{CO}_{2}$ and $\mathrm{O}_{2}$ molecules come from the bulk of the material. It is consistent with previous work, done by Luo et al., showing that both oxygen atoms from $\mathrm{O}_{2}$ gas come from the material in Li Rich NMC. ${ }^{25}$ Such findings suggest $\mathrm{O}$ - $\mathrm{O}$ pair formation occurs in LNTO during charge. Note, that there is no gas evolution during discharge implying that the formed $\mathrm{O}_{2}$ gas molecules do not reduce (Figure S13). 
a)
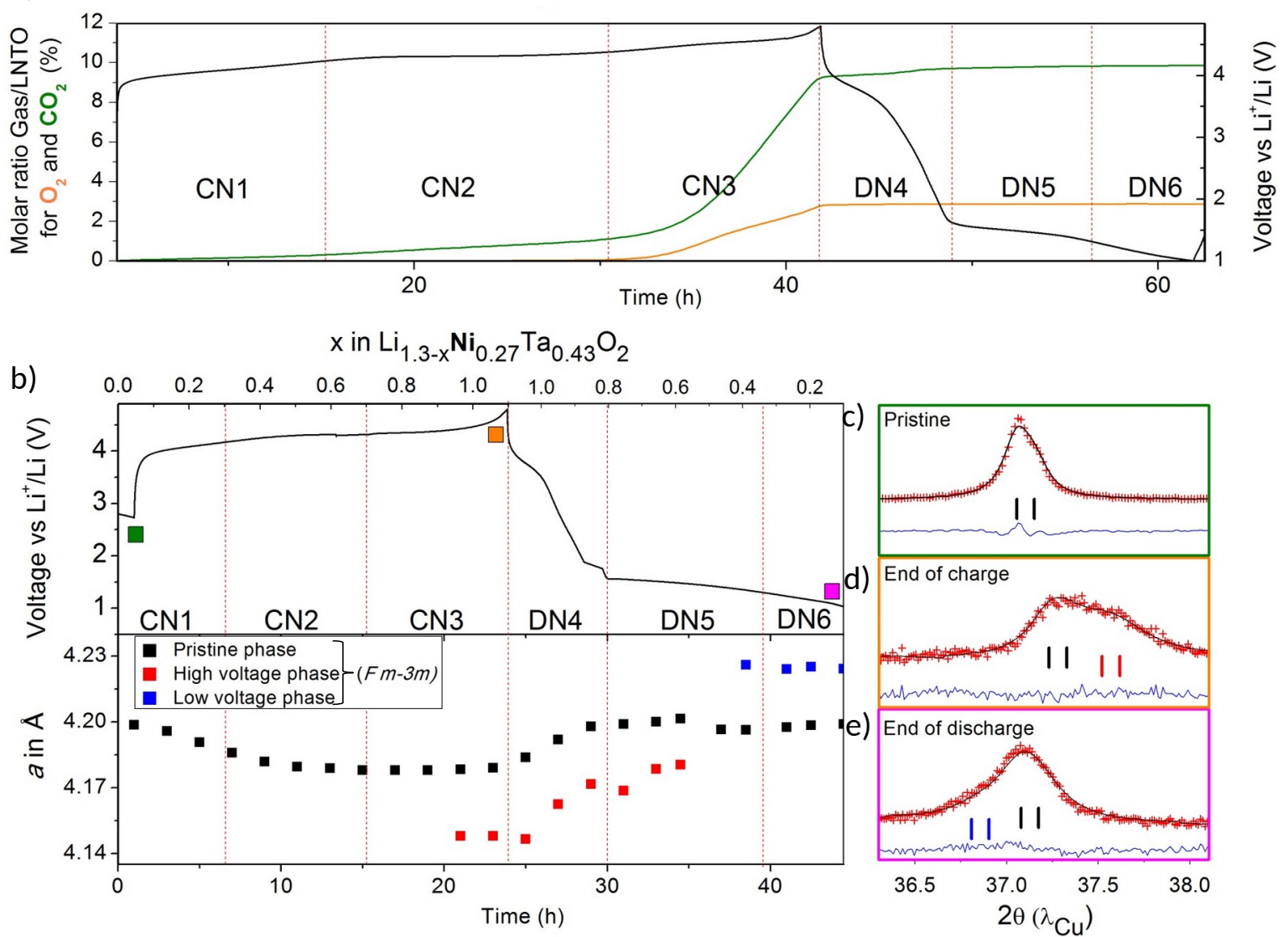

Figure $4:$ a) Molar ratio of $\mathrm{O}_{2} / \mathrm{LNTO}$ and $\mathrm{CO}_{2} / \mathrm{LNTO}$ measured via mass spectrometry during galvanostatic cycling together with the voltage-composition curve, in orange, green and black, respectively. b) Voltage-composition curve of the galvanostatic cycling during operando XRD measurement together with the cell parameter variation extracted from the patterns using Rietveld refinement. Black, red, and blue dots correspond to the cell parameters of the different phases. c-d-e) Rietveld refinement of specific patterns of the operando experiment. The red crosses, black continuous line and bottom blue line represent the observed, calculated, and difference patterns respectively. Vertical green tick bars are the Bragg positions. 
At this stage, it is important to check whether the release of oxygen at high potential is associated with structural changes, hence our motivation to perform operando X-ray diffraction. Figure 4 b-c-d-e) presents the electrochemical cycle and the result of the Rietveld refinement of the XRD patterns. We recall that the pristine crystallizes in a cubic space group F m -3 m, with therefore one cell parameter, a. During CN1, the cell parameter decreases gradually which is consistent with $\mathrm{Ni}$ oxidation $\left(\mathrm{Ni}^{2+} \rightarrow \mathrm{Ni}^{3+}\right)$, then stays constant through $\mathrm{CN} 2$ during which oxygen is oxidized but not released from the material. In the middle of CN3, when $O$ leaves the material, the appearance of a shoulder peak can be seen in the XRD pattern which can be indexed using the same space group as the pristine with however a smaller cell parameter, $4.148 \AA$ compared to $4.1990(10) \AA$ (Figure 4-d). The chemical composition of this new phase, now called "high voltage phase", could not be estimated due the overlap of its peaks with the pristine ones. During discharge, the cell parameters of both phases decrease and convert back to that of the pristine material with however a larger peak width indicative for the presence of strain, consistent with the XAS data.

Altogether these data provide an accurate description of the material's evolution during the first charge that can be schematically summarized in Figure 5). We could identify the origin of the voltage hysteresis, caused by drastically different charge and discharge potential for anionic redox. Looking for characteristics of anionic redox in LNTO, we found that it rapidly leads to $\mathrm{O}_{2}$ release upon oxidation together with structural evolution. To further understand the correlation between anionic redox and voltage hysteresis, a similar study is performed on LTMO which shows less hysteresis compared to LNTO. 
(Ni reduction)

(formation of densified phase)

\begin{tabular}{cccc} 
Charge & \multicolumn{2}{c}{$\begin{array}{c}\text { Oxygen oxidation } \\
+\mathrm{O}_{2} \text { release }\end{array}$} \\
$\begin{array}{c}\mathrm{Ni}^{2+} \rightarrow \mathrm{Ni}^{3+}(\mathrm{JT}) \\
\mathrm{X}=0\end{array} \mathrm{Oxygn}^{0.3}$ & 0.7 & 1.1
\end{tabular}
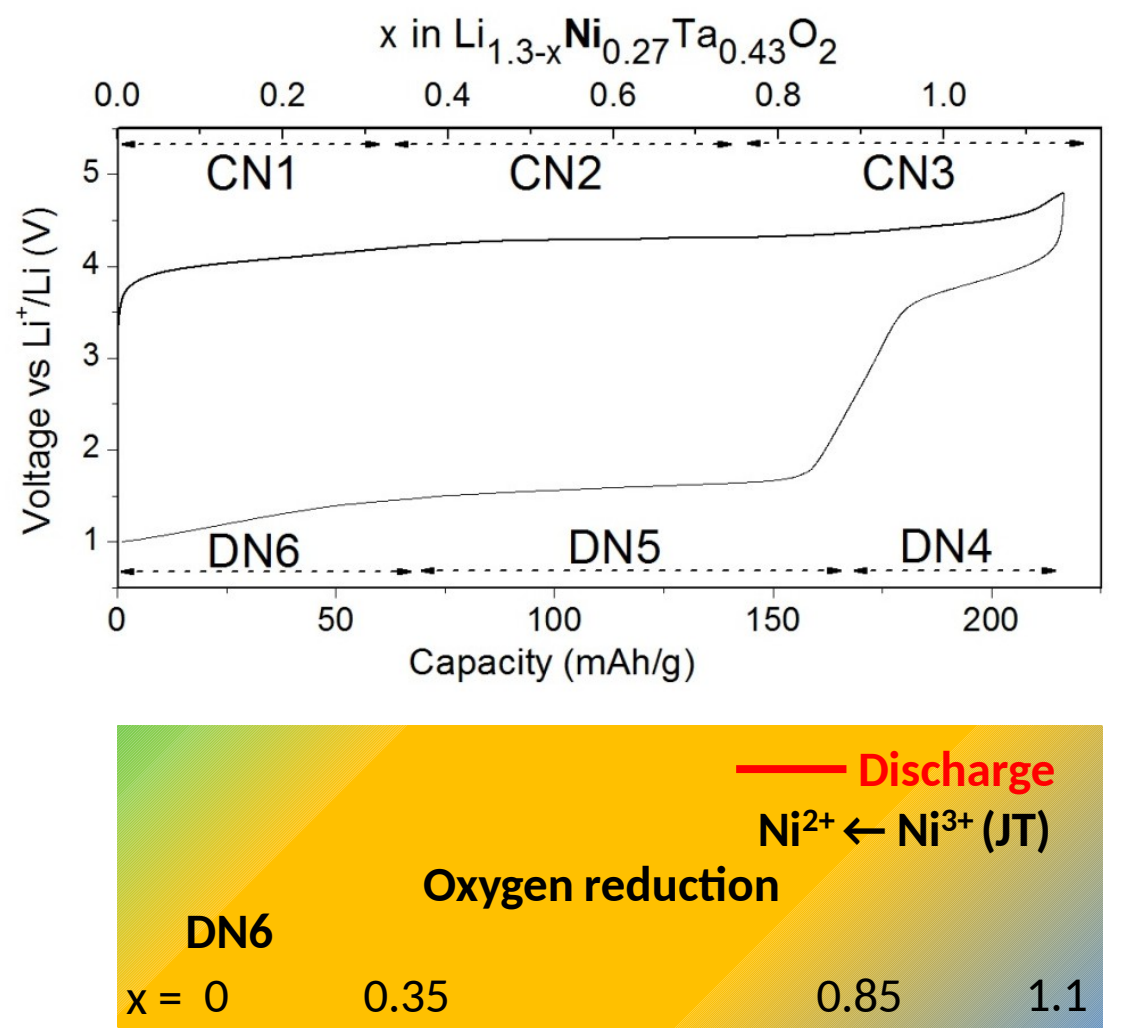

Figure 5: Schematics presenting the charge compensation mechanism in $\mathrm{Li}_{1.3} \mathrm{Ni}_{0.27} \mathrm{Ta}_{0.43} \mathrm{O}_{2}$

Mechanism of Li removal/uptake in $\mathrm{Li}_{1.3} \mathrm{Mn}_{0.4} \mathrm{Ta}_{0.3} \mathrm{O}_{2}$

The voltage-composition curve for $\mathrm{Li}_{1.3} \mathrm{Mn}_{0.4} \mathrm{Ta}_{0.3} \mathrm{O}_{2}$ is shown Figure 6 a) together with its dQ/ $\mathrm{dV}$ profile. We observe two oxidation peaks at $3.9 \mathrm{~V}(\mathrm{CM} 1)$ and $4.5 \mathrm{~V}$ (CM2) which correspond to the removal 0.4 and $0.5 \mathrm{Li}$, respectively, and two reduction peaks, one well pronounced at $3.4 \mathrm{~V}(\mathrm{DM} 3)$ and another one (DM4) spread in voltage (3-1 V) corresponding to the insertion of 0.6 and $0.2 \mathrm{Li}$. Following the same procedure as for the Ni-based compound, we could deduce that both $\mathrm{CM} 1$ and $\mathrm{CM} 2$ are merged into DM3 in discharge 
showing the irreversibility of the redox chemistry (Figure 6 b). Moreover note that DM4 appears only after charging at high SOC, hence its straight correlation with CM2. By comparison with the voltage-composition profile for the Ni-based compound, we observe that the abrupt potential jump upon reduction is replaced, in the Mn-phase, by a smoother decay and a lower polarization as deduced from GITT measurements Figure $6 \mathrm{c}$ ).
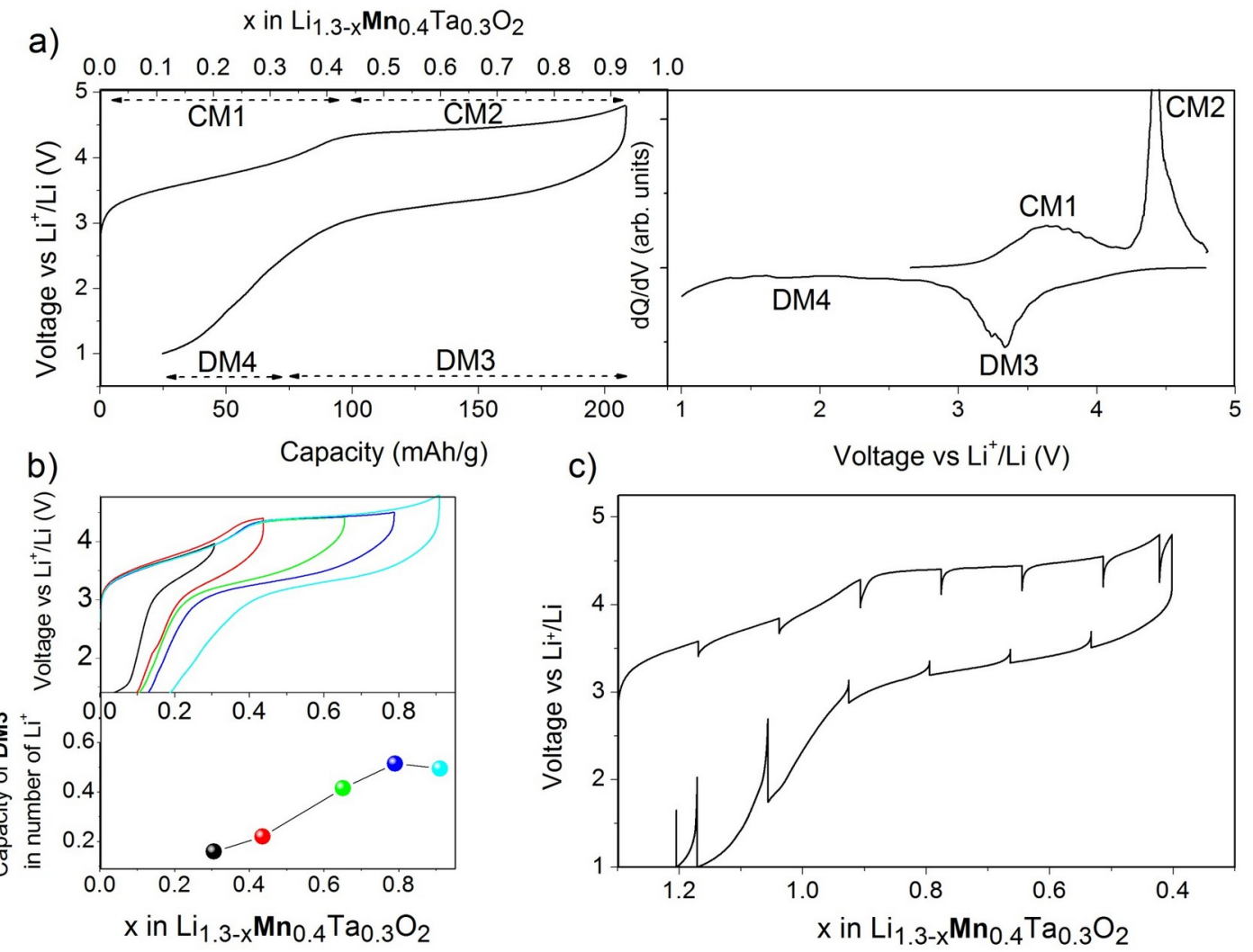

Figure 6: a) Voltage-composition curve of the $1^{\text {st }}$ galvanostatic cycle of LMTO together with its $\mathrm{dQ} / \mathrm{dV}$ profile emphasizing the $\mathrm{CM} 1, \mathrm{CM} 2$, DM3 and DM4 processes. b) $1^{\text {st }}$ galvanostatic cycle at different SOC together with the discharge capacity, in number of $\mathrm{Li}$, of DM3 (>3 V) in the bottom panel. c) GITT of the $1^{\text {st }}$ cycle of LMTO.

Once again, XAS was performed to access the charge compensation mechanism in $\mathrm{Li}_{1.3} \mathrm{Mn}_{0.4} \mathrm{Ta}_{0.3} \mathrm{O}_{2}$ and the results are shown in Figure 7 and Figure S14. Following the Mn Kedge position during operando measurement and comparing it with the reference spectra of $\mathrm{Mn}_{2} \mathrm{O}_{3}\left(\mathrm{Mn}^{3+}\right)$ and $\mathrm{Mn}_{2} \mathrm{O}_{4}\left(\mathrm{Mn}^{4+}\right)$, it can be concluded that $\mathrm{Mn}$ is $3+$ in the pristine material, 
oxidizes to $\mathrm{Mn}^{4+}$ during the first part of the charge (CM1) and remains as such afterwards (CM2). On discharge, $\mathrm{Mn}^{4+}$ is continuously reduced back to $\mathrm{Mn}^{3+}$ through DM3 and DM4.

The data were further exploited using PCA coupled to MCR-ALS analysis. Seven components were needed to describe the evolution of $\mathrm{Mn}$ oxidation state and environment during $\mathrm{Li}$ removal/insertion. The evolution of the concentrations of the reconstructed components together with the analysis of their EXAFS oscillations are presented in Figure $7 \mathrm{~b}-\mathrm{c}$ ), Figure S15 and Table S4, while the XANES part is shown in Figure S16. In short, in the pristine compound, $\mathrm{Mn}^{3+}$ sits in a Jahn-Teller distorted environment which converts back to a regular one when $\mathrm{Mn}^{3+}$ is oxidized ( during CM1). Upon further oxidation (CM2), the $\mathrm{Mn}$ environment distorts while its oxidation state remains constant (4+) implying a non-pasive role of the anionic network. During reduction, the Mn environment converts back to the pristine following nearly the same transformation while Mn continuously reduces from +4 to +3. These findings were further confirmed by ex situ Mn K-edge and L2/3-edge data as presented in Figure S17 and Figure S18. 


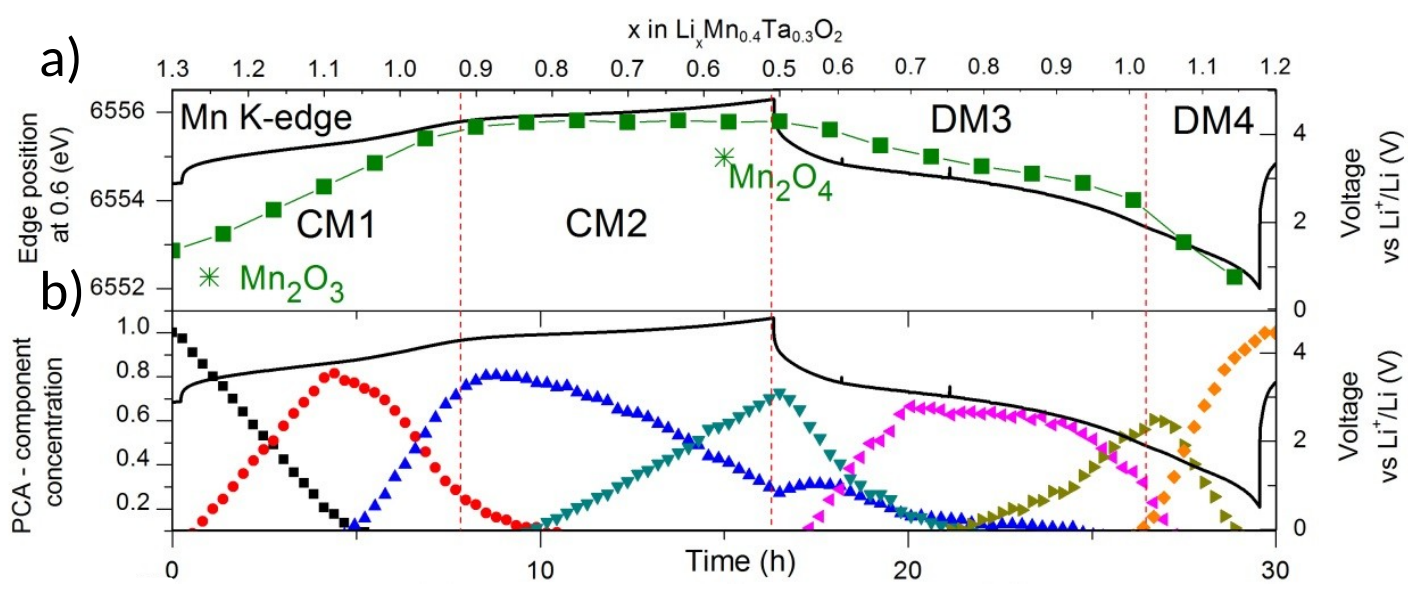

c)

\begin{tabular}{|c|c|c|c|c|c|c|}
\hline \multirow{2}{*}{$\begin{array}{l}\text { EXAFS fitting of PCA } \\
\text { components }\end{array}$} & \multicolumn{6}{|c|}{$1^{\text {st }}$ shell Mn - O } \\
\hline & $\mathrm{CN}$ & $d(M n-O)$ & $\mathrm{CN}$ & $d(M n-O)$ & Av. & $\Delta_{\mathrm{M}-\mathrm{O}} \times 10^{3}$ \\
\hline $\mathrm{Mn}^{3+}$ Jahn-Teller & 4 & $1.934(8)$ & 2 & $2.32(4)$ & 2.064 & 7.88 \\
\hline Intermediate & 5 & $1.91(2)$ & 1 & $2.35(15)$ & 1.983 & 5.76 \\
\hline $\mathrm{Mn}^{4+}$ regular & 6 & $1.901(4)$ & & & 1.901 & 0 \\
\hline $\mathrm{Mn}^{4+}$ distorted & 4 & $1.885(4)$ & 2 & $2.394(14)$ & 2.054 & 13.6 \\
\hline $\mathrm{Mn}^{3.7+}$ « regular » & 2 & $1.811(15)$ & 4 & $1.943(3)$ & 1.899 & 1.15 \\
\hline Intermediate & 5 & $1.918(5)$ & 1 & $2.32(5)$ & 1.986 & 5.86 \\
\hline $\mathrm{Mn}^{3+}$ Jahn-Teller & 4 & $1.928(5)$ & 2 & $2.29(3)$ & 2.049 & 7.2 \\
\hline
\end{tabular}
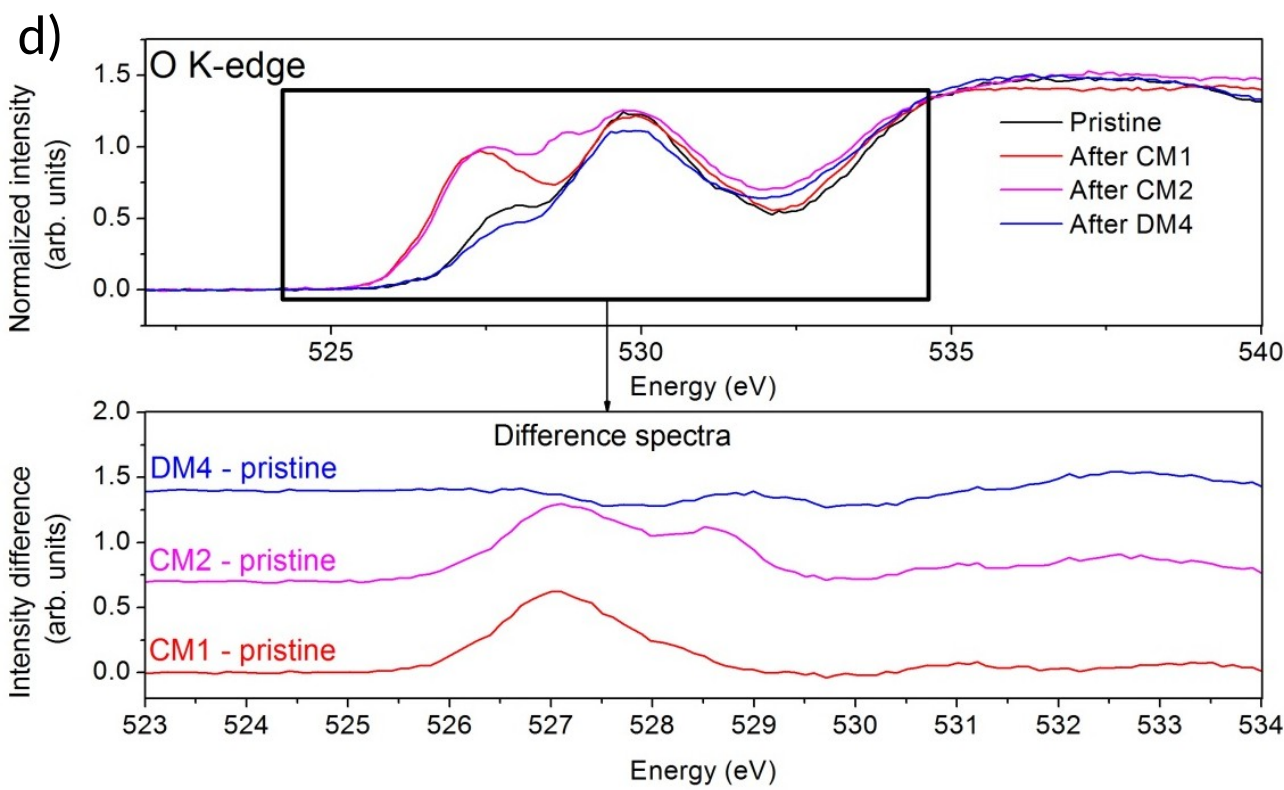

Figure 7: Evolution of the Mn K-edge position, in green, during operando measurement for the $1^{\text {st }}$ cycle together with the voltage composition curve, in black. b) Concentration evolution obtained by MCR-ALS during the operando measurement, dots, together with the galvanostatic cycling in black. c) Table summarizing the principal information extracted from 
the EXAFS fitting. Oxidation states indicates in the table are obtained assuming a linear correlation between edge position and oxidation state d) TFY O K-edge XAS spectra for ex situ samples during the charge and discharge, together with the difference spectra between the pristine and the spectra of the ex situ samples in the bottom insert.

Next, ex situ Ta $\mathrm{L}_{3}$-edge XAS were measured after CM1, CM2, DM3 and DM4 to assess to participation of $\mathrm{Ta}$ in the redox mechanism. From the data presented in Figure S19, Figure S20 and Table S5, nearly no change can be observed in the XANES or EXAFS region proving $\mathrm{Ta}$ is inactive during the electrochemical cycle. At this stage, to interrogate the oxygen activity, ex situ $\mathrm{O}$ K-edge spectra collected on samples recovered from $\mathrm{Li}_{1.3} \mathrm{Mn}_{0.4} \mathrm{Ta}_{0.3} \mathrm{O}_{2} / \mathrm{Li}$ cells stopped at the end of CM1 (4.2 $\mathrm{V}$ and $\mathrm{x}=0.4), \mathrm{CM} 2(4.8 \mathrm{~V}$ and $\mathrm{x}=0.9)$ and DM4 (1 V and $x=1.2$ ). The results are shown in Figure $7 a$ together with the spectra differences, processed as before, with the main evolution centered at $527 \mathrm{eV}$ and $528.7 \mathrm{eV}$. From $\mathrm{O}$ pDOS calculated via DFT (Figure S21), we can attribute the $527 \mathrm{eV}$ feature to $\mathrm{Mn}-\mathrm{O}$ states which is consistent with the observed intensity increase during CM1 and its constancy through CM2. Similarly, the second peak at $528.7 \mathrm{eV}$ which increases during $\mathrm{CM} 2$ is attributed to the anionic redox bearing in mind that $\mathrm{Mn}$ and $\mathrm{Ta}$ are inactive in this region. It is worth mentioning that in both LNTO and LMTO, the O K-edge feature associated to anionic redox appears at the same energy. This is consistent with the fact that anionic redox involves the oxidation of non-bonding levels which energy only depends on electrostatic interactions being of similar amplitude in LNTO and LMTO. Overall, it results that both compounds show anionic redox activity associated to a voltage hysteresis which is quite larger for LNTO as compared to LMTO, hence the need to understand the origin of this difference.

To check the outcome of the anionic redox species in LMTO, we performed OEMS. No gas evolution was detected through CM1 while a copious amount of $\mathrm{CO}_{2}$ which is likely coming from electrolyte decomposition is observed afterwards (CM2). Minute traces of $\mathrm{O}_{2}$ towards the extreme end of the charge are observed in contrast with the large $\mathrm{O}_{2}$ release observed for the Ni-based compound. Further assessing the difference between LNTO and LMTO, operando XRD has been carried on. Figure 8 a) presents the voltage-composition curve together with the XRD patterns and the $a$ cell parameter obtained from Rietveld refinement. 
Interestingly, a decreases from 4.1975(11) $\AA$ to 4.129 (3) $\AA$ during $\mathrm{Mn}^{3+} / \mathrm{Mn}^{4+}$ oxidation, in agreement with EXAFS data, and then remains constant while showing a peak broadening. A continuous decrease of $a$ is observed on the subsequent discharge. We should recall that under the same oxidation process we have note the appearance of an extra phase in LNTO samples.

a)

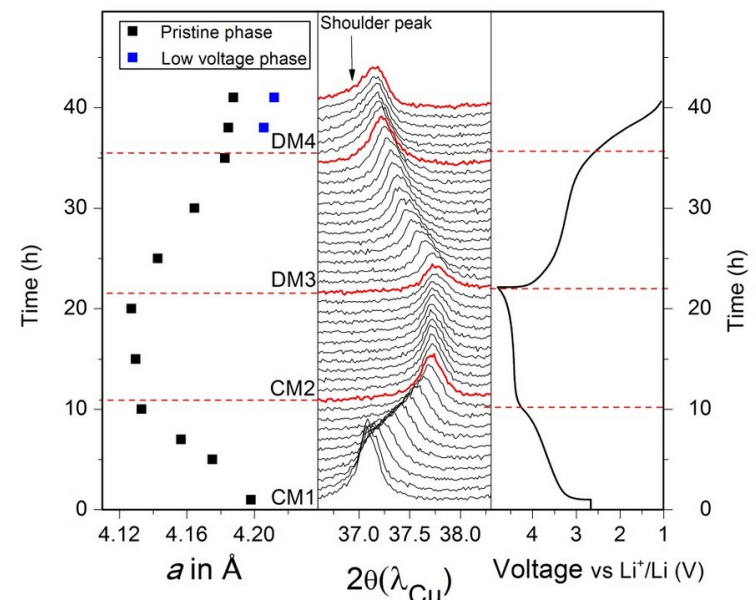

b)

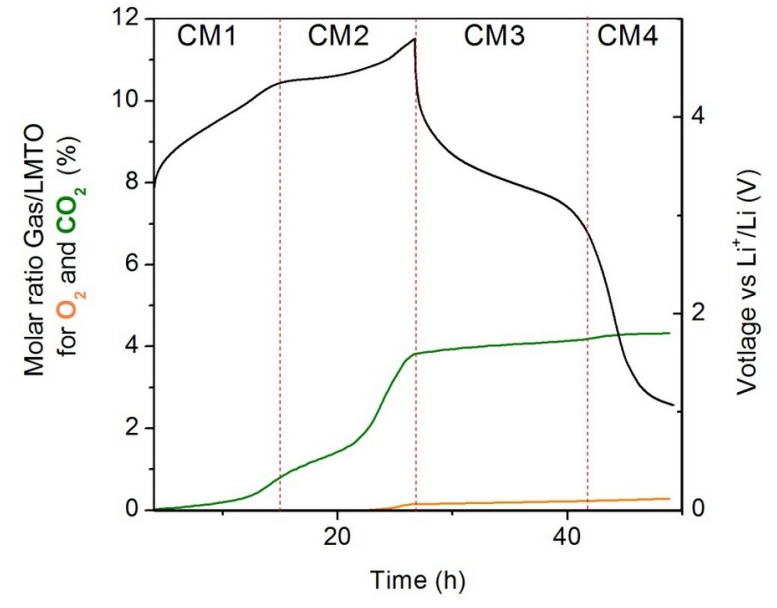

Figure 8: a) Voltage-composition curve, patterns and cell parameters extracted from Rietveld refinement of the operando XRD measurement from right to left. B) OEMS results for LMTO, showing the evolution of the molar ratio between $\mathrm{O}_{2}$ and $\mathrm{CO}_{2}$ and the active material, in orange and green, together with the galvanostatic cycling data in black.

Overall through complementary operando techniques, we can propose for $\mathrm{Li}_{1.3} \mathrm{Mn}_{0.4} \mathrm{Ta}_{0.3} \mathrm{O}_{2}$ the electrochemical reactivity path schematized in Figure 9. It drastically differs from the one previously established for LNTO by the anionic reduction potential which is of 3V for LMTO as opposed to $1.5 \mathrm{~V}$ for LNTO. Additionally, a greater stability of LMTO over LNTO against $\mathrm{O}_{2}$ release was observed. Next, we try to rationalize this finding by DFT calculations. 

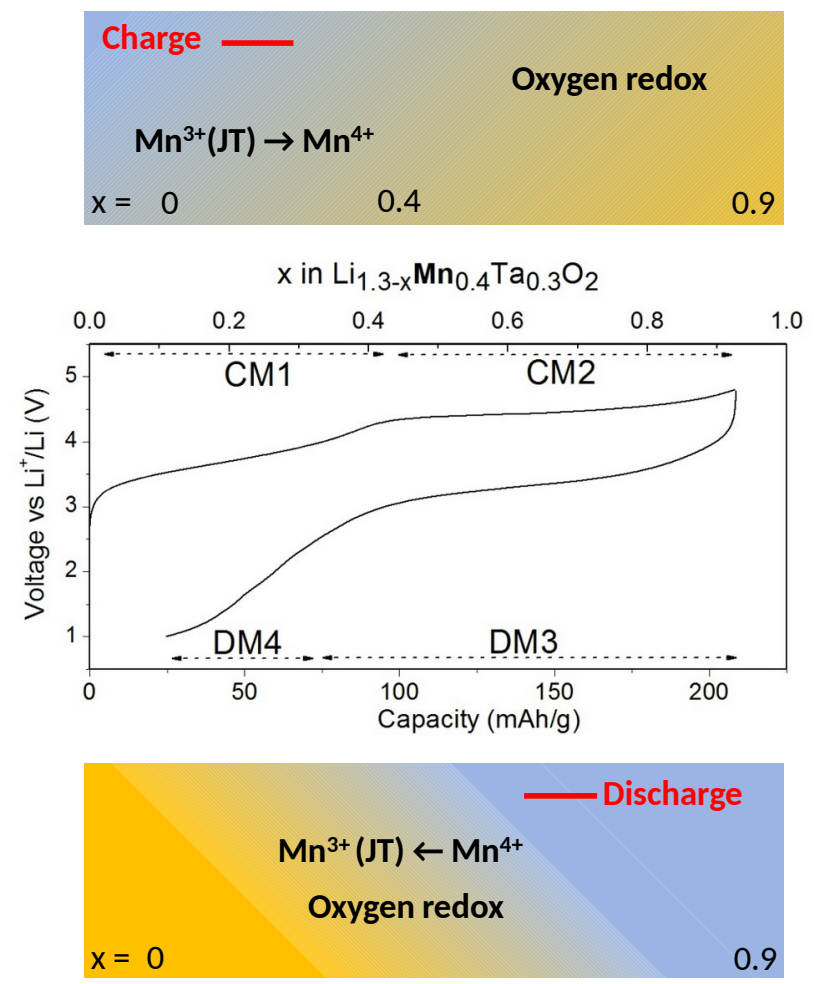

Figure 9: Schematics representing the charge compensation mechanism for $\mathrm{Li}_{1.3} \mathrm{Mn}_{0.4} \mathrm{Ta}_{0.3} \mathrm{O}_{2}$

\section{Understanding the different anionic redox mechanisms using DFT calculations}

DFT calculations were performed to determine the electronic band structure evolution of both materials upon delithiation. They are shown in Figure 10-a and Figure S24. Pristine $\mathrm{Li}_{1.3} \mathrm{Ni}_{0.3} \mathrm{Ta}_{0.4} \mathrm{O}_{2}$ compound displays a large Mott-Hubbard band gap, consistent with the strong electronic stabilization expected for a half-filled system $\left(\mathrm{Ni}^{2+} \mathrm{t}_{2 \mathrm{~g}}{ }^{6} \mathrm{e}_{\mathrm{g}}{ }^{2}\right.$ electronic configuration) ${ }_{\underline{2}}^{26}$ The partially oxidized phase $\mathrm{Li}_{0.9} \mathrm{Ni}_{0.3} \mathrm{Ta}_{0.4} \mathrm{O}_{2}$ displays a narrow charge transfer gap, denoted as $\Delta_{C T}$ in Figure 10-b, due to the Jahn-Teller distortion of $\mathrm{Ni}^{3+}$. Amusingly, the partial delithiation of $\mathrm{Li}_{1.3} \mathrm{Mn}_{0.4} \mathrm{Ta}_{0.3} \mathrm{O}_{2}$ into $\mathrm{Li}_{0.9} \mathrm{Mn}_{0.4} \mathrm{Ta}_{0.3} \mathrm{O}_{2}$ leads to the reverse scenario. The narrow Jahn-Teller band gap $\left(\mathrm{Mn}^{3+}\right)$ for pristine LMTO becomes a wide charge transfer gap in the oxidized sample due to the large Mott splitting of the $\mathrm{Mn}^{4+}$ half-filled $\mathrm{t}_{2 \mathrm{~g}}{ }^{3}$ states. This difference in charge transfer gaps prior the occurrence of the anionic activity is at the origin of the different anionic redox mechanism. 


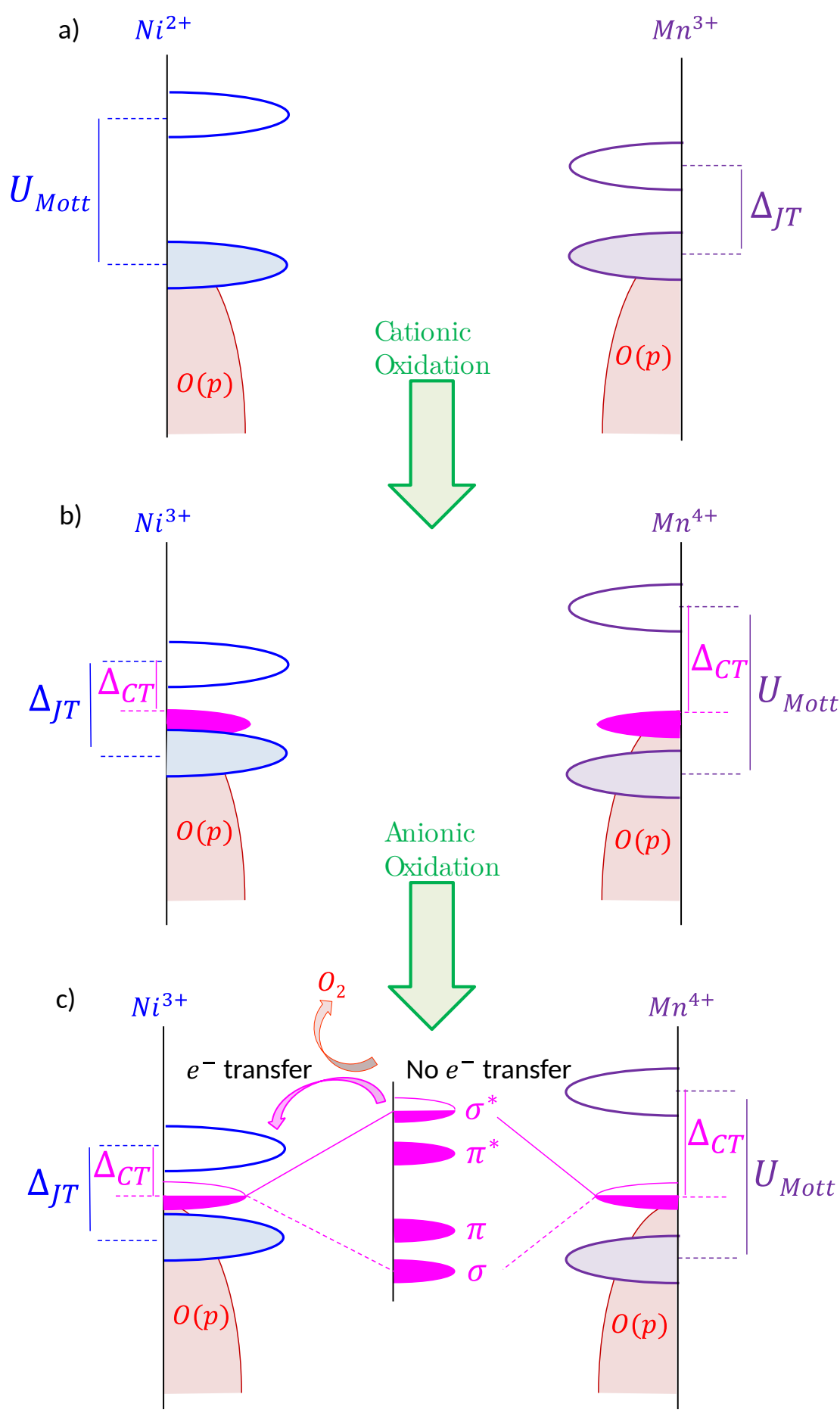

Figure 10: a), b) and c) are schematics of the Density of State (DOS) for pristine LNTO and LMTO, after the cationic process and during the anionic process, respectively. Blue, purple, magenta and red states stand for $\mathrm{Ni}-\mathrm{O}^{*}, \mathrm{Mn}-\mathrm{O}^{*}, \mathrm{O}$ non-bonding and $\mathrm{O}(2 \mathrm{p})$ states, respectively. 
During anionic redox, for both compounds the top portion of the non-bonding oxygen band (magenta) is emptied during anionic redox. Bearing in mind that we are dealing with disordered structure the oxygen non-bonding states are not equal with respect to their cationic environment, therefore the first oxidized oxygen atoms are those having the lowest cationic charge in their first coordination shells, as shown Figure S27. Their oxidation leads to the formation of $\mathrm{O}-\mathrm{O}$ dimers having $\sigma, \pi, \pi^{*}$ and $\sigma^{*}$ discrete bands, ${ }^{24}$ with the $\pi^{*}$ and $\sigma^{*}$ states being as high in energy as the O-O bond is short. When these antibonding states cross the first empty metallic band, electron transfer from the $O$ to the metal is expected, leading to $\mathrm{O}_{2}$ release together with the reduction of the transition metal (Figure $10 \mathrm{c}$ ). This situation is exemplified by the Ni-based material showing a small charge transfer band gap, significant $\mathrm{O}_{2}$ release together with $\mathrm{Ni}$ reduction. In contrast, the $\Delta_{C T}$ in the $\mathrm{Mn}$-based compound is larger enough to stabilize the oxidized oxygen species preventing $\mathrm{O}_{2}$ release. Turning to the discharge, as long as the $\sigma^{*}$ of the oxygen level remains lower than the first empty $M$ band, no hysteresis is expected, and we will have the following sequence cation $\rightarrow$ anion (charge) and anion $\rightarrow$ cation (discharge) redox processes. In contrast, for in the LNTO case, the sequence is inversed: cation $\rightarrow$ anion and cation $\rightarrow$ anion for charge and discharge, respectively. Lastly, if the $\sigma^{*}$ and transition metal states are roughly at the same energy, cationic and anionic redox could proceed simultaneously in reduction, as found for LMTO.

At this stage a remaining question regards the large difference in the anionic redox potential between LMTO $(3 \mathrm{~V})$ and LNTO (1.5V). A likely explanation is rooted in our previous described inversion redox process for LNTO with the metallic reduction affecting the nature of the anionic species and hence their reduction potential.

\section{DISCUSSION :}

We have provided a detailed description of the evolution of two new disordered rocksalt compounds during $\mathrm{Li}$ insertion/removal, namely $\mathrm{Li}_{1.3} \mathrm{Ni}_{0.27} \mathrm{Ta}_{0.43} \mathrm{O}_{2}$ and $\mathrm{Li}_{1.3} \mathrm{Mn}_{0.4} \mathrm{Ta}_{0.3} \mathrm{O}_{2}$. First, we found these materials to have similar characteristics than the Nb-based or Ti-based ones previously reported, suggesting that their redox mechanism is nearly transparent to the nature of $d^{0}$ transition metals provided they have similar ionic radii [ceder diffusion update when published]. Second, we demonstrate that both compounds show anionic redox reactivity with a few differences, namely a higher hysteresis and instability against $\mathrm{O}_{2}$ release 
in the Ni-based compound. We introduce the notion of charge transfer band gap to account for such a difference.

Turning to the origin of the voltage drop in the discharge curve, already observed in other disorder rocksalt phases $\left(\mathrm{Li}_{1.2} \mathrm{Ni}_{0.33} \mathrm{Ti}_{0.33} \mathrm{Mo}_{0.16} \mathrm{O}_{2}\right)$ showing anionic redox activity, it was proposed to be nested in kinetic limitations associated with diffusion/migration. ${ }^{5}$ However, the constancy of the voltage hysteresis whatever the current rate applied, as experimentally determined suggests that thermodynamics plays a key role as well. Besides, cationic migration in Li-rich layered oxides has also been proposed as source of the voltage hysteresis. ${ }^{24}$ This claim is not inconsistent with our model, since cationic migration triggers new oxygen environment, depleted in charge, hence affecting the relative position of the oxygens states with respect to the band gap so that hysteresis can occur.

These findings open new perspectives to design Li-based disordered rocksalt compounds showing anionic redox with limited voltage hysteresis provide that we can tune the band gap. Several clues can be formulated. First, transition metals suffering electronic instabilities such $\mathrm{Fe}^{4+}\left(\mathrm{d}^{4}\right)$ and $\mathrm{Ni}^{3+}\left(\mathrm{d}^{7}\right)$ should be banned, unless we could stabilize $\mathrm{Fe}^{5+}\left(\mathrm{d}^{3}\right)$ which is quite unlikely without high chemical/physical pressure. Concerning the $\mathrm{Ni}$, destabilizing the $\mathrm{Ni}^{3+}$ to the expense of the $\mathrm{Ni}^{4+}$ by decreasing the framework covalency could be attractive. Along that line, Ceder et al. proposed the partial substitution of $\mathrm{O}$ by $\mathrm{F}$ to successfully increase $\mathrm{Ni}$ oxidation in $\mathrm{Li}_{1.2} \mathrm{Ni}_{0.33} \mathrm{Ti}_{0.33} \mathrm{Mo}_{0.16} \mathrm{O}_{2}$, but with a limited effect on the hysteresis due the narrow substitution range. ${ }^{27}$ An alternative strategy has been the use of other closed shells metals like $d^{10}$ in $\mathrm{Li}_{1.15} \mathrm{Ni}_{0.52} \mathrm{Sb}_{0.38} \mathrm{O}_{2}$ or $\mathrm{Li}_{4} \mathrm{NiTeO}_{6}$ favoring the $\mathrm{Ni}^{2+} / \mathrm{Ni}^{4+}$ redox couple but with the drawback of suppressing the anionic redox activity. ${ }^{28,29}$ An attractive midway scenario could consist in mixing $\mathrm{d}^{0}$ and $\mathrm{d}^{10}$ cations to have $\mathrm{Ni}^{4+}$ coexisting with anionic redox. At last, using the charge transfer band gap as an indicator, it appears that $\mathrm{Mn}$ is the best element for disordered rocksalt phases showing both anionic redox and low hysteresis. Whether purely coincidentally or not the recently reported disordered rocksalt phases $\mathrm{Li}_{1.2} \mathrm{Mn}_{0.4} \mathrm{Ti}_{0.4} \mathrm{O}_{2}$ and $\mathrm{Li}_{4} \mathrm{Mn}_{2} \mathrm{O}_{5}(\mathrm{RT})$ show hysteresis of $0.6 \mathrm{~V}\left(50^{\circ} \mathrm{C}\right)$ and $1.3 \mathrm{~V}(\mathrm{RT})$, respectively. ${ }^{30}$ 


\section{Conclusions :}

Ni-based disordered rocksalt, having anionic redox activity, suffer low energy efficiency due to the presence of a voltage drop during discharge, in contrast to the Mn-based ones. To elucidate the origin of this behavior, we reported the comparison between two new disordered rocksalt compounds, $\mathrm{Li}_{1.3} \mathrm{Ni}_{0.27} \mathrm{Ta}_{0.43} \mathrm{O}_{2}$ and $\mathrm{Li}_{1.3} \mathrm{Mn}_{0.4} \mathrm{Ta}_{0.3} \mathrm{O}_{2}$, which show anionic redox activity. We found that the voltage drop is nested in the anionic redox mechanism, which is dependent on the nature of the transition metal through the charge transfer gap but not on the type of $d^{0}$ substituted element. Indeed, in the Ni-based compound, the presence of a Jahn-Teller $\mathrm{Ni}^{3+}$ during charge leads to the formation of a narrow charge transfer band gap triggering $\mathrm{O}_{2}$ release and $\mathrm{Ni}$ reduction upon anionic oxidation, and hysteresis and voltage drop in the subsequent discharge. In contrast, in the Mn-based compounds, due the presence of $\mathrm{Mn}^{4+}$ which shows half-filled $\mathrm{t}_{2 \mathrm{~g}}{ }^{3}$, a large charge transfer band gap is found stabilizing oxidized oxygen species and therefore leading to weak $\mathrm{O}_{2}$ release and moderate hysteresis. In the light of these findings, we give guidelines to design the electronic structure of Li-ion battery cathode material enhancing anionic redox performances.

\section{Author Information:}

\section{Corresponding Author: Jean-marie.tarascon@college-de-france.fr}

\section{Author contributions:}

Q.J. carried out the synthesis, Q.J conducted the electrochemical measurements, Q.J. and G.R. did the diffraction experiments and analysis, Q.J. and A.I. conducted the hard XAS measurements and analysis, Q.J, H.L, J.C. conducted for soft XAS experiments and analysis, E.J.B conducted the OEMS experiments, Q.J., M.S. and M.-L.D. performed the DFT study, Q.J., G.R., M.-L.D. and J.M.T. wrote the manuscript, and all authors discussed the experiments and edited the manuscript.

\section{Acknowledgement:}


The authors thank Vivian Nassif for her help in neutron diffraction experiment at the D1B diffractometer at ILL. The authors thank J. Vergent for his help in programing. The authors also thank V. Briois and S. Belin for helpful discussions on XAS analysis and synchrotron SOLEIL (France) for providing beamtime at the ROCK beamline (This work was supported by a public grant overseen by the French National Research Agency (ANR) as part of the "Investissements d'Avenir" program (reference : ANR10-EQPX45), proposal \#20160095). Q. J. thanks the ANR "Deli-Redox" for PhD funding. J.-M.T. acknowledges funding from the European Research Council (ERC) (FP/2014)/ERC Grant-Project 670116-ARPEMA.

References

(1) Tarascon, J.-M.; Armand, M. Issues and Challenges Facing Rechargeable Lithium Batteries. Nature 2001, 414 (6861), 359-367.

(2) Lee, J.; Urban, A.; Li, X.; Su, D.; Hautier, G.; Ceder, G. Unlocking the Potential of CationDisordered Oxides for Rechargeable Lithium Batteries. Science 2014, 343 (6170), 519522.

(3) Yabuuchi, N.; Takeuchi, M.; Nakayama, M.; Shiiba, H.; Ogawa, M.; Nakayama, K.; Ohta, T.; Endo, D.; Ozaki, T.; Inamasu, T.; et al. High-Capacity Electrode Materials for Rechargeable Lithium Batteries: $\mathrm{Li}_{3} \mathrm{NbO}_{4}$-Based System with Cation-Disordered Rocksalt Structure. Proc. Natl. Acad. Sci. 2015, 112 (25), 7650-7655.

(4) Yabuuchi, N.; Nakayama, M.; Takeuchi, M.; Komaba, S.; Hashimoto, Y.; Mukai, T.; Shiiba, H.; Sato, K.; Kobayashi, Y.; Nakao, A.; et al. Origin of Stabilization and Destabilization in Solid-State Redox Reaction of Oxide Ions for Lithium-Ion Batteries. Nat. Commun. 2016, 7, 13814.

(5) Lee, J.; Seo, D.-H.; Balasubramanian, M.; Twu, N.; Li, X.; Ceder, G. A New Class of High Capacity Cation-Disordered Oxides for Rechargeable Lithium Batteries: Li-Ni-Ti-Mo Oxides. Energy Env. Sci 2015, 8 (11), 3255-3265.

(6) Yabuuchi, N.; Ohzuku, T. Novel Lithium Insertion Material of LiCo1/3Ni1/3Mn1/3O2 for Advanced Lithium-Ion Batteries. J. Power Sources 2003, 119-121, 171-174.

(7) Kumakura, S.; Komaba, S.; Kubota, K. Li4MeWO6 ( $\mathrm{Me}=\mathrm{Ni}, \mathrm{Mn}, \mathrm{Co}$ ) As Positive Electrode Materials for Li-Ion Batteries. Meet. Abstr. 2015, MA2015-02 (6), 481-481.

(8) Yabuuchi, N.; Tahara, Y.; Komaba, S.; Kitada, S.; Kajiya, Y. Synthesis and Electrochemical Properties of Li4MoO5-NiO Binary System as Positive Electrode Materials for Rechargeable Lithium Batteries. Chem. Mater. 2015.

(9) COLIN, J.-F.; Bourbon, C.; JACQUET, Q. Cathode Material for Li-lon Batteries. WO2017098113A1, June 15, 2017.

(10) Zhao, W.; Yamaguchi, K.; Sato, T.; Yabuuchi, N. Li ${ }_{4 / 3} \mathrm{Ni}_{1 / 3} \mathrm{Mo}_{1 / 3} \mathrm{O}_{2}-\mathrm{LiNi}_{1 / 2} \mathrm{Mn}_{1 / 2} \mathrm{O}_{2}$ Binary System as High Capacity Positive Electrode Materials for Rechargeable Lithium Batteries. J. Electrochem. Soc. 2018, 165 (7), A1357-A1362.

(11) Urban, A.; Abdellahi, A.; Dacek, S.; Artrith, N.; Ceder, G. Electronic-Structure Origin of Cation Disorder in Transition-Metal Oxides. Phys. Rev. Lett. 2017, 119 (17), 176402. 
(12) Morcrette, M.; Chabre, Y.; Vaughan, G.; Amatucci, G.; Leriche, J.-B.; Patoux, S.; Masquelier, C.; Tarascon, J.-M. In Situ X-Ray Diffraction Techniques as a Powerful Tool to Study Battery Electrode Materials. Electrochimica Acta 2002, 47 (19), 3137-3149.

(13) Rodríguez-Carvajal, J. Recent Advances in Magnetic Structure Determination by Neutron Powder Diffraction. Phys. B Condens. Matter 1993, 192 (1-2), 55-69.

(14) Briois, V.; La Fontaine, C.; Belin, S.; Barthe, L.; Moreno, T.; Pinty, V.; Carcy, A.; Girardot, R.; Fonda, E. ROCK: The New Quick-EXAFS Beamline at SOLEIL. J. Phys. Conf. Ser. 2016, 712, 012149.

(15) Ravel, B.; Newville, M. ATHENA, ARTEMIS, HEPHAESTUS: Data Analysis for X-Ray Absorption Spectroscopy Using IFEFFIT. J. Synchrotron Radiat. 2005, 12 (4), 537-541.

(16) Massart, D. L. (Desiré L.; 1941-. Handbook of Chemometrics and Qualimetrics; Elsevier, 1997.

(17) Juan, A. de; Jaumot, J.; Tauler, R. Multivariate Curve Resolution (MCR). Solving the Mixture Analysis Problem. Anal. Methods 2014, 6 (14), 4964-4976.

(18) He, M. Elucidating Interface Reactions in Li-Ion Batteries and Supercapacitors by in Situ Gas Analysis. Doctoral Thesis, ETH Zurich, 2016.

(19) Kresse, G.; Furthmüller, J. Efficiency of Ab-Initio Total Energy Calculations for Metals and Semiconductors Using a Plane-Wave Basis Set - ScienceDirect. Computational Materials Science. 6th ed. 1996, pp 15-50.

(20) Kresse, G.; Hafner, J. Ab Initio Molecular Dynamics for Liquid Metals. Physical Review B. 1993, p 558.

(21) Perdew, J. P.; Burke, K.; Ernzerhof, M. Generalized Gradient Approximation Made Simple. Phys. Rev. Lett. 1996, 77 (18), 3865-3868.

(22) Dudarev, S. L.; Botton, G. A.; Savrasov, S. Y.; Humphreys, C. J.; Sutton, A. P. ElectronEnergy-Loss Spectra and the Structural Stability of Nickel Oxide: An LSDA+ U Study. Phys. Rev. B 1998, 57 (3), 1505.

(23) Assat, G.; Foix, D.; Delacourt, C.; Iadecola, A.; Dedryvère, R.; Tarascon, J.-M. Fundamental Interplay between Anionic/Cationic Redox Governing the Kinetics and Thermodynamics of Lithium-Rich Cathodes. Nat. Commun. 2017, 8 (1).

(24) Gent, W. E.; Lim, K.; Liang, Y.; Li, Q.; Barnes, T.; Ahn, S.-J.; Stone, K. H.; McIntire, M.; Hong, J.; Song, J. H.; et al. Coupling between Oxygen Redox and Cation Migration Explains Unusual Electrochemistry in Lithium-Rich Layered Oxides. Nat. Commun. 2017, 8 (1), 2091.

(25) Luo, K.; Roberts, M. R.; Hao, R.; Guerrini, N.; Pickup, D. M.; Liu, Y.-S.; Edström, K.; Guo, J.; Chadwick, A. V.; Duda, L. C.; et al. Charge-Compensation in 3d-Transition-MetalOxide Intercalation Cathodes through the Generation of Localized Electron Holes on Oxygen. Nat. Chem. 2016, 8 (7), 684-691.

(26) de' Medici, L. Hund's Coupling and Its Key Role in Tuning Multiorbital Correlations. Phys. Rev. B 2011, 83 (20).

(27) Lee, J.; Papp, J. K.; Clément, R. J.; Sallis, S.; Kwon, D.-H.; Shi, T.; Yang, W.; McCloskey, B. D.; Ceder, G. Mitigating Oxygen Loss to Improve the Cycling Performance of High Capacity Cation-Disordered Cathode Materials. Nat. Commun. 2017, 8 (1), 981.

(28) Sathiya, M.; Ramesha, K.; Rousse, G.; Foix, D.; Gonbeau, D.; Guruprakash, K.; Prakash, A. S.; Doublet, M. L.; Tarascon, J.-M. Li4NiTeO6 as a Positive Electrode for Li-Ion Batteries. Chem. Commun. 2013, 49 (97), 11376.

(29) Ma, X.; Kang, K.; Ceder, G.; Meng, Y. S. Synthesis and Electrochemical Properties of Layered LiNi2/3Sb1/3O2. J. Power Sources 2007, 173 (1), 550-555. 
(30) Freire, M.; Kosova, N. V.; Jordy, C.; Chateigner, D.; Lebedev, O. I.; Maignan, A.; Pralong, V. A New Active Li-Mn-O Compound for High Energy Density Li-Ion Batteries. Nat. Mater. 2015. 